\title{
Sex and the Mission: The Conflicting Effects of Early Christian Missions on HIV in sub-Saharan Africa*
}

\author{
Julia Cagé $\mathrm{e}^{\dagger 1}$ and Valeria Rueda ${ }^{\ddagger 2}$ \\ ${ }^{1}$ Sciences Po Paris and CEPR \\ ${ }^{2}$ University of Nottingham
}

September 25, 2019

\begin{abstract}
This article investigates the long-term impact of historical missionary activity on HIV in subSaharan Africa. On the one hand, missionaries were the first to invest in modern medicine in the region. On the other hand, Christianity influenced sexual beliefs and behaviors that affect the risk of contagion. We build a new geocoded dataset locating Protestant and Catholic missions in the early 20th century, as well as the health facilities they invested in, that we combine with individual-level DHS data. With these data, we can address separately these two channels, within regions close to historical missionary settlements. First, we show that proximity to historical missionary health facilities decreases the likelihood of HIV; persistence in healthcare provision and safer sexual behaviors in the region explain this result. Second, we show that regions close to historical missionary settlements exhibit higher likelihood of HIV. This effect is driven by the Christian population in our sample. This suggests conversion to Christianity as a possible explanatory channel. Our findings are robust to alternative specifications addressing selection.
\end{abstract}

Keywords: Africa; Christianity; Historical persistence; Missions; Healthcare infrastructure; HIV / AIDS; Sexual behaviors .

JEL No: D72; N37; N77; 033; Z12; Z13.

\footnotetext{
${ }^{*}$ We gratefully acknowledge the many helpful comments and suggestions from Brian A'Hearn, Bob Allen, Yann Algan, Steve Broadberry, Sascha Becker, Yannick Dupraz, Rui Esteves, James Fenske, Elise Huillery, Jane Humphries, Jean-Louis Keene, Michael Koelle, Sara Lowes, Nathan Nunn, Kevin O'Rourke, Jared Rubin, Avne Offer, Pauline Rossi, and Paul Seabright. We are also grateful to participants at the ASREC, LAGV, the Warwick-Political Economy of Development, and the World Economic History conferences; as well as to seminar participants in the universities of Los Andes, Bonn, Exeter, Glasgow, Harvard, Monash, Nottingham, Oxford (ESH and CSAE), the Paris School of Economics, Queen Mary, el Rosario, Sciences Po, and Warwick. We thank Marcella Alsan for sharing her tsetse fly suitability index data with us. Sidhart Bhushan provided outstanding research assistance. This research was generously supported by Oxford University's John Fell Fund. All errors are our own.

${ }^{\dagger}$ Sciences Po Paris. julia [dot] cage [at] sciencespo [dot] fr

${ }^{\ddagger}$ Corresponding author. School of Economics, University of Nottingham. valeria [dot] rueda [at] nottingham [dot] ac [dot] uk
} 


\section{Introduction}

A large literature has shown that colonial shocks, from the slave trade and forced labor, to indirect rule and education policies, shaped development in the long-run (among others Nunn, 2008; Lange, 2004; Dell, 2010: Wantchekon et al. 2015) 1 Less-well understood is how these shocks have determined outcomes today. Most cases studied entailed institutional, cultural, and structural transformations, which all together induced persistent economic change. An important question is then to determine the ways in which these elements relate to different dimensions of development. In this paper, we focus on a specific case where we can separate a technological and a cultural mechanism: the effect of Christian missions on HIV in Africa. On the one hand, missionaries pioneered the advancement of western medicine in the early 20th century. On the other hand, conversion to Christianity produced beliefs and behaviors that affect the risk of contagion. Comparing missions that invested in health facilities with those that did not, and the Christian population with the rest, we can separately address cultural from infrastructural effects.

UNAIDS estimates that around 36.9 million people were living with HIV as of 2017, and more than two-thirds of them live in Africa ${ }^{2}$ As such, it is one of the deadliest pandemics in modern history, and an important obstacle to development in many countries. This article delves into the question of the historical determinants of this disease in Africa, by focusing on the long-term consequences of early Christian missionaries on HIV. We hypothesize that two distinct forces can have influenced the disease: provision of healthcare and conversion to Christianity.

[Figure 1 about here.]

On the one hand, missionaries were almost the only ones providing Western medical services to the African population, from their early expansion in middle of the $19^{\text {th }}$ century throughout the colonial period. Both Protestant and Catholic missionaries, many of whom were doctors and nurses, indeed pioneered the development of Western healthcare facilities for the indigineous population (Vaughan, 1991, Ch.3) $\mathrm{H}^{3}$ Historical health provision matters for two main reasons. First, the literature in African medical history and public health has shown the persistence of missionary healthcare (Ranger, 1981; Good, 1991), a fact that this paper also corroborates. Health centers today can affect HIV prevalence because they distribute anti-retrovirals and are the epicenters of

\footnotetext{
${ }^{1}$ See Michalopoulos and Papaioannou (forthcoming) for a recent review of this literature.

${ }^{2}$ While prevalence is very high in this region of the world, it also varies strongly from one country to the other, see Figures 1 and, in the online Appendix B.1.

${ }^{3} \mathrm{~A}$ number of medical campaigns were also implemented by colonial military forces (see e.g. Lowes and Montero. 2017b.
} 
awareness and testing campaigns.$^{4}$ Second, even without infrastructure persistence, a healthier population in the past can have slowed the spread of HIV because other STDs, such as syphilis, greatly increase the likelihood of contagion.5 These diseases were already known, public health campaigns were designed to prevent them, and treatments against the disease or their symptoms started improving from the early $20^{\text {th }}$ century (de Sousa et al. 2010; Doyle et al., 2018).

On the other hand, missions, and particularly Protestant missions, left a profound cultural imprint. Their ultimate objective, after all, was to convert the local population to Christianity, an enterprise in which they succeeded in the long run (Hastings, 1996; Nunn, 2010). Christianity is today the most common religion in Africa, and it is a religion that imposes a great number of explicit and implicit constraints on sexual behaviors (monogamy, abstinence outside and before marriage, or taboos over contraception for certain denominations, etc.) $6^{6}$ The transformations of family structures and sexual behaviors brought about by Christianity can have ambiguous effects on HIV. Strict monogamy can protect against HIV as it reduces the risk of contagion (Bertocchi and Dimico. 2015); however, sequential or unfaithful monogamy strongly correlates with larger HIV prevalence in Africa, because it leads to a more connected sexual network than polygyny (Reniers and Watkins, 2010). Beyond the constraints imposed on practicants' sexual behaviors, Christianity may have had a broader sphere of influence on HIV. Local churches are involved in the design and implementation of many campaigns and sex-education curricula (Dupas, 2011; Duflo et al., 2015; Mash and Mash. 2013: Dupas et al. 2018). This article thus proposes to address separately two forces, healthcare provision and conversion, through which early Christian missionaries may have influenced HIV in the long run.

To do so, we have completed a novel dataset of early Protestant and Catholic mission settlements in sub-Saharan Africa, that also accounts for their health facilities. For Protestant missions, we rely on an original dataset released with a previous article (Cagé and Rueda, 2016). The Protestant data was compiled using the 1903 Geography and Atlas of Christian Missions (Beach, ed, 1903). We complement these data with an entirely new dataset on Catholic missions and their health facilities. This dataset was compiled from the 1929 Atlas Hierarchicus (Streit, 1929), a publication from the Vatican's Congregation for the Propagation of Faith (Sacra Congregatio de Propaganda Fide). For each settlement, we documented its coordinates, the geographic and historical characteristics, as

\footnotetext{
${ }^{4}$ With today's anti-retroviral treatments, the risk of contagion for a patient taking correctly their medication is virtually nil.

${ }^{5}$ Syphilis multiplies by 2 to 5 times the likelihood of coital HIV transmission (Pépin, 2011).

${ }^{6}$ This expansion was visible even before the explosion of American-funded Pentecostal movements in the second-half of the $20^{\text {th }}$ century. For the early 1950s, the World Christian database reports above 40 million adherents for sub-Saharan African Christianity, and above 1.8 million new adherents per year.
} 
well as whether there was an investment in health facilities. Because there is a twenty-year gap between the two sources, we complement the data on health facilities for former British colonies by geocoding all the health facilities reported in the British Blue Books up to 1920. We merge these data with contemporary individual-level geocoded data from the Demographic and Health Survey compiled by USAID (DHS). The DHS are standardized nationally representative surveys in developing countries that collect biomarker data on HIV.

Our econometric analysis deals with two forms of selection. First, historical and geographical characteristics might have determined mission station location, preventing the comparison between regions close and far from these settlements. Early European missionaries, either Protestant or Catholic, did choose to locate in geographically favored areas that ultimately urbanized (Johnson. 1967: Nunn, 2010: Akyeampong et al., eds, 2014; Cagé and Rueda, 2016: Jedwab et al., 2018), and we know that HIV is a disease of urban areas that are well connected into the transport network (Fox. 2010: Pépin, 2011; Oster, 2012). Second, different missionary stations invested in different activities such as health or education. There may be endogenous selection of missions into these activities.

To address selection in missionary locations, we follow Cagé and Rueda (2016) and restrict our sample to regions near historical mission settlements. Because regions near missions shared similar geographic, institutional and cultural environments, this restriction isolates the specific effect of the investments from other possible long-term determinants of development that might be correlated with missionary location. We find that historical missionary presence is associated with higher probability of being tested positive for HIV. Ceteris paribus, a location $10 \mathrm{~km}$ away from a mission has a $11 \%$ higher average HIV probability than one $20 \mathrm{~km}$ away. Importantly, our results are robust to focusing on the most urbanized areas. Regarding the mechanisms at play, we show that this effect is driven by the Christian population in our sample, and that this population exhibits riskier sexual behaviors. Furthermore, we investigate the long-term impact of proximity to a mission on nonsexually transmitted diseases. We show that, unlike for HIV, proximity to missions is not associated with higher prevalence of anemia, the other biomarker reported in our data. Our findings thus suggest that conversion to Christianity is a possible mechanism to understand the worsening of HIV in regions exposed to historical missions. This result is consistent with the biomedical and historical literature on HIV in Africa.

To address selection of missions into health investments, we first note that differences between missions with and without health facilities suggest that health facilities were located in areas with larger population densities and closer to pre-colonial population settlements. If geographically con- 
founding factors were driving our results, we would expect these locations to have larger, and not smaller HIV risk, because population density is one of the strongest determinants of HIV. However, there might still be other confounders affecting, within missions, both selection into health and HIV risk. Therefore, we control for observable geographic and historical covariates (among which ruggedness, suitability to Tse-Tse fly (Alsan, 2015), and distance to other missionary facilities) 7 We show that, within regions close to missions, proximity to a historical missionary health facility decreases the likelihood of HIV. Ceteris paribus, a location $10 \mathrm{~km}$ away from a historical health facility has a 7\% lower average HIV probability than one $20 \mathrm{~km}$ away. We then develop a matching strategy that aims at isolating the effect of proximity to a mission with a health facility from the effect of proximity to a mission with similar characteristics, but that did not provide health services. The results are robust to this approach and of similar order of magnitude. Furthermore, we assess the bias due to unobservables using the sensitivity of the treatment to added controls (Oster, 2016).

Finally, we provide evidence that the persistence of health infrastructure, and safer sexual norms, rather than the practice of safer sex, can explain the effect $\left.\right|^{8}$ In particular, we show that living in regions close to health investments also relates to better access to health care today, and decreases the likelihood of using of sex workers' services, the number of sexual partners other than spouse and the number of sexual partners over the lifetime.

Although we cannot ultimately separate the effect of health investments from other mission characteristics, all of our results taken together point in the direction that historical health investments played a role in determining HIV today. We are also aware of the difficulty in separating the effect of missionary presence from potential confounders, in particular urbanization. However, the robustness of our results to different strategies, the fact that they hold even when concentrating on very well-connected locations, and that they seem driven by the Christian population, all suggest that missionary presence and conversion are also relevant historical determinants of HIV.

Related literature This article contributes to the growing literature in economics on the historical and social determinants of health outcomes, in particular STDs. A number of papers have aimed at understanding differences in prevalence. Oster (2005) shows theoretically that differences between African countries can be attributed to differences in sexual behavior (e.g. the number of sexual partners), male circumcision, and the timing of the epidemic. Oster (2012) provides empirical evidence

\footnotetext{
${ }^{7}$ We also control extensively for the determinants of HIV prevalence that have been highlighted in the existing literature, in particular we account for the time travel to a urban area, a measure of connectedness into the transport infrastructure, which is an important determinant of HIV (Oster, 2005, 2012).

${ }^{8}$ This channel is consistent with results found by Calvi and Mantovanelli [2018) in the case of India.
} 
of a positive relationship between exports and new HIV infections. Bertocchi and Dimico (2015) study the long-term effects of family structure and sexual behavior (in particular polygyny) on HIV prevalence in sub-Saharan Africa, and Alsan and Cutler (2010, 2013) investigate the mechanisms behind HIV decline in Uganda. Anderson (2018) shows that the legal origins of the formerly colonized sub-Saharan African countries determines current day female HIV rates. We contribute to this literature by investigating the role played by historical determinants. To the extent of our knowledge, Mantovanelli (2016) is the only other paper considering the impact of missionary activities on HIV. He compares the effect of Protestant and Catholic missions on contemporary levels of HIV, and finds that Catholic missions are associated with lower levels of HIV infection and explores the role of sexual behaviors to explain this pattern. We complement his work using more information at the mission level. Since our data identifies missions that provided health services, we can estimate the effect of health infrastructure. Moreover, we also devote attention to the role of conversion to Christianity, a cultural mechanism not considered in his work.

The early work of Protestant missionaries has been largely associated with improving development in the long term, through an increase in social capital (Woodberry, 2012: Cagé and Rueda. 2016), human capital (Gallego and Woodberry, 2010: Acemoglu et al., 2014; McCleary, 2015; Waldinger. 2017; Valencia-Caicedo, 2018), or gender equality (Akyeampong et al., eds, 2014, Chap. 16). Calvi and Mantovanelli (2018) study the positive long-term consequences of Protestant missions in India on health outcomes (individuals' body mass index). In this article, we tell a more nuanced story as we establish that Christian missions had conflicting effects on HIV $]^{9}$

Our article is more broadly related to the literature on the persistent effect of historical events on economic development. As noticed by Feyrer and Sacerdote (2009) and Huillery (2009, 2011), historical events can explain heterogeneous development dynamics. Micro-oriented studies isolate specific channels through which a development dynamic can be durably established (Nunn, 2008: Huillery, 2009: Alesina et al., 2011; Michalopoulos and Papaioannou, 2013, 2016; Voigtländer and Voth, 2012; Jha, 2013; Grosfeld and Zhuravskaya, 2015; Dell et al., 2017). Early investments are of particular importance in the case of sub-Saharan Africa (see e.g. Wantchekon et al., 2015) 10 Lowes and Montero (2017b) document the extent to which exposure to colonial medical campaigns affect trust in modern medicine today, and in particular consent to take a blood test for HIV. They also consider health outcomes and provide evidence that the colonial medicine campaigns are associated

\footnotetext{
${ }^{9}$ On the long-term determinants of beliefs and behaviors and the cultural origins of comparative development, see also Miguel et al. (2008); Grosjean (2014); Grosjean and Khattar (2014); Michalopoulos et al. (2016); Moscona et al. (2017).

${ }^{10}$ There is also an extensive literature on the long-run impacts of colonial institutions. See e.g. Dell (2010); Dell and Olken (2017) and Lowes and Montero (2017a) among many others.
} 
with higher levels of HIV in Cameroon.

Finally, our paper complements the growing literature in economics on HIV prevention (Dupas, 2011: Mash and Mash, 2013: Duflo et al., 2015, Dupas et al., 2018) 11 In accordance with this literature, we show that the Christian influence can be associated with an increased HIV prevalence. Moreover, we document the role played by sexual behaviors (see e.g. DellaVigna and Ferrara, 2015) 12

The rest of the paper is organized as follows. Section 2 presents a brief historical background on missionary activity in sub-Saharan Africa, the early investments in modern medicine and the focus of a number of religious groups on abstinence until marriage. Section 3 describes the new dataset we build for this paper and presents summary statistics. In Section 4 , we provide empirical evidence on the long-term impact of missionary activity on the likelihood of HIV, and disentangle the positive effect of health investments and the negative effect of the focus on abstinence. Section 5 presents a number of robustness checks. The endogenous selection of missions into health investments is extensively discussed. Section 6 investigates the channels that could explain the persistent effect of missionary presence, in particular missionary health investments, conversion, and the role played by family values, sexual behaviors and beliefs. Section 7 concludes.

\section{Historical background}

This section draws on the historical and medical literature on missions and on the origins of HIV to show that missionaries may have influenced HIV prevalence in the long run. Two links emerge. First, missions are tightly linked to the development of modern medicine in sub-Saharan Africa, which may have helped contain the epidemic through: (i) the investments themselves, as medical centers persisted (Doyle et al. 2018) and medical campaigns aimed at diffusing information, family planning, screening, and distributing anti-retroviral may have helped contain the disease; (ii) the early treatment against other STDs that increase the risk of HIV contagion may have similarly done so. Second, missions, as they changed religious and cultural practices, may have affected HIV. Conversion to Christianity indeed disrupted family structures, in particular polygyny that is associated with lower HIV prevalence. Moreover, Christian institutions today, which are partly a missionary legacy, have faced difficulties campaigning to contain the disease in an effective way.

\footnotetext{
${ }^{11}$ See also Baird et al. (2012) who find that in Malawi, monthly cash transfers to the families of out-of-school girls significantly reduced HIV infection rates after 18 months.

${ }^{12}$ Thornton (2008) finds that when people learn they are HIV positive they increase their purchase of condoms.
} 
The missionary roots of modern medical provision in sub-Saharan Africa. The history of modern medicine in sub-Saharan Africa is closely linked to the development of missionary activity. Missionaries were among the first to provide modern health care until the middle of the twentieth century (Vaughan, 1991, Ch.3). Missionary work was often conducted by doctors or nurses. David Livingstone - probably the best-known figure in the history of African missionaries - was a doctor himself. Although Livingstone's project was the promotion of trade with local populations as means to improve development and end the slave trade, he emphasized the crucial role of health and education because "neither civilization nor Christianity can be promoted alone. In fact, they are inseparable." "Civilization", roughly understood as the advancement of economic prosperity and Western values of which Western medicine was an essential part, was thus considered a central element of the evangelical mission from an early period.

From the end of the nineteenth century to the early twentieth century, there was a rapid increase in medical work among missionaries. The Edinburgh Medical Missionary Association was founded in 1841. In 1891, the Church Mission Society established a new "Medical Committee" that was specifically in charge of managing the medical work of the society. Medical missionaries had a central role in the provision of health care through the construction of hospitals, dispensaries, the provision of midwifery services, the treatment of leprosy, vaccination campaigns, and the training of lay health workers. Although the colonial methods employed, such as the segregation of lepers in asylums, are now questioned, the case remains that an important part of the provision of health care was initiated by missionaries. Moreover, secular investments in health partly relied on the Christian missionary networks. For a more detailed history, refer to Vaughan (1991, Chap. 5).

The early Christian provision of health-care thus persisted after colonization and has been particularly influential in the design of contemporary health-care in low-income countries (Idler, 2014). In 1968, for instance, the World Council of Churches established the Christian Medical Commission $(\mathrm{CMC})$, institutionalizing the long-lasting tradition of Christian medical and healing work around the world 13 In 2001, the World Christian Encyclopedia inventoried 37 different Christian societies working on the provision of health-care in sub-Saharan Africa (unfortunately, more detailed statistics are not reported). The Christian Medical Fellowship (CMF), a modern medical Christian society, also illustrates the extent of the Christian influence in contemporary medical provision. It inven-

\footnotetext{
${ }^{13}$ E.g., according to Pr. Dan Kaseje's address to the WHO on the contribution of the CMC to health-care in Africa, policies such as the essential drugs initiative in 1987 (or Bamako initiative), that aimed at "solving the problems in the financing of primary health-care" and lead to the commitment of Africa health ministers to ensure a regular supply of drugs, were put together by the WHO and UNICEF following the guidelines of the CMC. A transcript of this speech can be found online, with additional examples of joint projects between the CMC and the WHO.
} 
tories on its website 64 Christian partner hospitals ${ }^{14}$, many of them with satellite institutions and mobile clinics. In countries like Malawi or Rwanda, the CMF's partner institutions alone account for up to $9 \%$ of the country's total hospital beds.

The Christian roots of modern health provision. Missionaries' central objective was to convert the local population to the Christian faith, and to some extent, missionary medicine was considered by some as instrumental towards this goal. The notion of healing the body and soul is indeed deeply rooted in the Christian dogma. For instance, the Gospel of Matthew 10:1 reads: "Jesus called his twelve disciples to him and gave them authority to drive out impure spirits and to heal every disease and sickness". Medical work - a form of "healing authority" - was "part of a programme of social and moral engineering through which Africa would be saved" (Hardiman, ed, 2006). The following excerpt from Vaughan (1991, p. 72), narrating an encounter between a missionary doctor and a traditional healer, is also illustrative of how medical missionary work was sometimes conceived as embedded in the evangelization work, rather than as an independent scientific activity.

"I asked him [the traditional healer] if he had any medicine that would make a man live forever. He fumbled in his basket, (...) he showed me some earth, scraped from the surface of a cliff on a river bank, and told me that it should be mixed with castor oil and used for anointing the body, so that the body may prosper. 'But even so', he added pathetically, 'we still die'. I told him that WE HAVE the Medicine for immortality (...) and it was to be had in Church."

Therefore, when studying the legacy of missionary activity on health outcomes, we need to bear in mind that missionary medicine was a part of a larger conversion enterprise. The history of the early colonial and missionary campaigns targeting sexually transmitted diseases (STDs) illustrates the tension between the Christian and the scientific response to these diseases. In Uganda, there was a large increase in the prevalence of syphilis from the mid-nineteenth century, which led to the first public health campaigns launched in sub-Saharan Africa by the colonial powers (Setel, 1999, p.99) 15 The priority of the campaigns was not the treatment of patients or the diffusion of scientifically accurate information, but the fight against what colonial authorities considered to be the innate

\footnotetext{
${ }^{14}$ These hospitals are located in Angola, Cameroon, Central African Republic, Chad, Congo, DRC, Ethiopia, Kenya, Madagascar, Malawi, Niger, Nigeria, Rwanda, Senegal, Sierra Leone, South Africa, Tanzania, Uganda, Zambia, and Zimbabwe.

${ }^{15}$ The medical history of the Ugandan syphilis outbreak has actually shown that the event was largely overestimated, because an endemic and non-dangerous form of syphilis was initially mistaken by the venereal syphilis (Davies, 1956). This, however, does not affect our historical analysis.
} 
sinfulness of the African society (Vaughan, 1991). This moral combat was in turn supposed to eradicate the "disease of immorality", the term used by missionary doctor Albert Cook to refer to syphilis in Uganda (Vaughan, 1991, p. 138). The interventions by colonial powers, missionaries, and local authorities to fight the crisis took different forms, but they always implied the necessity to change sexual behaviors by incentivizing monogamous marriages at a younger age. Missionaries campaigned for the recognition of customary law marriages in 1918, capping the levels of required bride wealth, banning divorce for reasons other than adultery, and imposing restriction on women's mobility (Doyle, 2013).

However, the prioritizing of morality over medical responses cannot be generalized to all missionaries. A revealing example can be found in the archives of the Society for the Propagation of the Gospel (SPG) ${ }^{16}$ Around 1907, as a response to the SPG's inquiry on the needs of their missionaries in the field, Reverend Lattimer Fuller, a missionary doctor in South Africa, replied with a letter that reads rather like a public health report than a moralizing pamphlet. Without references to a moralizing enterprise, he simply emphasizes the need for dispensaries ("cottage hospitals") and funds to train personnel, to contain a growing epidemic of syphilis: ${ }^{17}$

"The usual medical estimate of the health of the million Natives in this diocese is that seventy five percent of them suffer more or less from syphilis, and not less than twenty five percent from incipient or advanced phthisis. (...) At this stage [the phthisis] can be easily and successfully treated, only there is no one to treat it. (...) Nothing would be really of much use in such densely populated a district [Johannesburg] except something in the way of a cottage hospital where two or three native girls would be trained to look after the sick."

The role of medical missions in the development of Western medicine in sub-Saharan Africa, beyond its instrumental value for conversion, is also emphasized in the historical work on Protestant and Catholic medical missions. For instance, Good (1991) writes: "The idea that medical care for Africans should be subordinate to the goal of spiritual salvation - especially strong among Protestant missions - gradually tempered to accommodate the practical view that the treatment of disease, relief of suffering, and training of Africans as medical auxiliaries constituted worthy ideals of Christian service in their own right."

\footnotetext{
${ }^{16}$ Bodleian Library, Papers of the United Society for the Propagation of the Gospel 1701-1980.

17 "Papers of the United Society for the Propagation of the Gospel - Papers of the Medical Mission Department" (Bodleian Library, 1701-1980, MM Box 48, 39). We reproduce the letter in its entirety in the online Appendix Section D.
} 
Medical missionaries, in fact, were extremely active in the diagnosis and treatment of many conditions, in particular sexually transmitted diseases. Exploring the specific case of the Uganda mission-hospital, Doyle et al.(2018) present the continuous efforts to diagnose and treat syphilis and other related STDs both for Christians and non-Christians, throughout the colonial period and after independence, when the missionary hospital was nationalized. The missionary doctors' efforts in the containment of STDs are likely to have mattered, as STD-related genital ulcers have been shown to be catalizers of the early spread of the HIV epidemic (de Sousa et al., 2010).

Today, medical missionaries continue to have an active role in the HIV-prevention campaigns, even when the messages diffused conflict with Christian dogmas. For instance, in 2009, the United Church of Christ HIV Ministry Network released a statement recommending that houses of worship and faith-based education institutions distribute condoms and provide comprehensive sexual education. Other HIV-relief programs also run by faith-based organizations are less clear on the importance of distributing condoms ${ }^{18}$ In this article, we capture this heterogeneity by comparing the effect of missions that specialized in health provision to those that did not. We show indeed that only regions around missions that invested in health exhibit lower HIV prevalence today.

Missions, Christianity, and HIV The history of African Christianity, and the way it shaped the HIV epidemic from its very roots, goes beyond the historical and persistent provision of public health. In this section, we show that there is both historical and contemporary evidence suggesting that early exposure to Christianity could have affected HIV prevalence. This evidence provides grounds for our investigation into the long-term consequences of missionary presence on HIV.

Recent research at the intersection between history and biology has shown that the origins of HIV in Africa can be traced back to the first half of the $20^{\text {th }}$ century. The evolution of HIV from a succesful cross-species contagion of SIV (Simian Immunodeficiency Virus, the "version" of HIV that contaminates monkeys) into a large-scale human epidemic is tightly linked to colonial history, and the way it brought up a large-scale rapid cultural and urban transformation. The 1920s are the estimated timing of the group-0 cross-species transmission between apes and humans (Hemelaar, 2012). The disease likely diffused after one or several incidents of cross-species contamination, around the Congo-river basin in the 1930s and 1940s. A single diffusion cause is impossible to identify, but it is believed that the contagion was made possible as a result of colonial transformations,

\footnotetext{
${ }^{18}$ We do not wish to dismiss the importance of such relief programs, as they have devoted substantial amounts of financial and human resources to support local community initiatives that provide treatment care for patients. Although they do discuss sexual education, their focus is often shifted, in terms of prevention, towards highlighting the importance of monogamy and the Christian life ("The untold story of African AIDS relief." United Methodist News, 28 March 2013).
} 
which changed local demographic structures, consolidated a commercial sex work industry, and facilitated the spread of diseases through poorly organized health campaigns that heavily relied on injectable medicines (Pépin, 2011: Lowes and Montero, 2017b).

Large scale public infrastructure projects, like the Congo-Océan railway project (1921-1932), and rapid urbanization, consolidated population centers with skewed sex ratios. In these population centers, the commercial sex work sector grew rapidly. Sex workers were highly prone to STDs leading to genital ulcers, which in turn highly increase the contagion risk of HIV (de Sousa et al. 2010). These centers were also frequently exposed to public health campaigns where frequent use of unsterilized needles facilitated iatrogenic diffusion.

By diffusing a religion that promoted changes in sexual behaviors and family structures, missionaries may have affected HIV since its very origins. Pépin (2011, p. 98), for instance, gives a glimpse on how missionaries, who actively discouraged polygamy and tried promoting monogamous marriages, may have contributed to the spread of the disease:

“By a strange paradox, the work of (...) missionaries led to unexpected outcomes. (...) missionaries pushed hard for the emancipation of women and the abolition of polygamy, directly and through the colonial authorities, while nuns developed activities aimed at improving the status of women. (...) No longer forced to have sexual relations with a man selected by their kin, some women opted for something that was easier to attain than the proposed idealistic monogamous union based on love and the Ten Commandments: the trade of sexual services."

It is not necessary to go as far as spanning a causality chain from Christianity to the sex industry to understand that conversion to Christianity may have affected HIV prevalence. For instance, missionaries devoted substantial efforts into diminishing polygyny, a marriage structure that today is associated with lower HIV prevalence, because it creates " small isolates of concurrent partnerships in which the virus is trapped" (Reniers and Watkins, 2010). This network is less likely to spread HIV than one where both men and women have multiple and changing partners ${ }^{19}$

Today, the focus of campaigns against HIV is often on teaching the ABC approach: "Abstain, Be Faithful, Condomize". But while religious groups have been open to teaching this message, there is qualitative evidence that the "Condomize" section is often ignored. Many churches - in particular

\footnotetext{
${ }^{19}$ Reniers and Watkins (2010) also explain the negative correlation between polygyny and HIV prevalence resulting from "coital dilution", the fact that polygynous marriages have less frequent sexual intercourse, thus decreasing the probability of transmission.
} 
Pentecostal churches - indeed consider the use of condoms to be a sin (Mash and Mash, 2013). Religious groups are also heavily involved in the design of sex-education curricula delivered in many public schools. According to Duflo et al.(2015), in Kenya as well as in many other sub-Saharan African countries, the resulting curriculum teaches the biology of AIDS and HIV transmission, how to care for people living with AIDS, and prevention. The prevention component stresses abstinence before marriage, followed by marital faithfulness as the most effective ways to prevent STDs. The official textbook does not mention condoms nor contraception ${ }^{20}$

Yet, it has been shown in the literature that HIV curricula stressing abstinence before marriage do not reduce risky sexual behaviors, whereas those that do explain the use of condoms are effective in the reduction of STDs (Dupas, 2011: Duflo et al., 2015; Dupas et al., 2018).

\section{Data and missionary locations}

\subsection{Historical data}

Different sources were used to construct the dataset of missions and historical controls. We describe them in turns in this section.

\subsubsection{Protestant missionary investments}

Regarding Protestant missions, we originally compiled the data of missionary investments and their locations in a previous article (Cagé and Rueda, 2016). We constructed the mission-level data and geocoded the maps of sub-Saharan African regions from the Geography and Atlas of Christian Missions (Beach, ed, 1903). The maps locate all the Protestant mission stations in 1903 (an example of these maps is provided in Figure 2b).

As opposed to other available geographic datasets of Protestant missions (Akyeampong et al., eds, 2014. Chap. 16), the one generated for this article contains detailed information for each mission settlement. In the Geography and Atlas of Christian Missions, each mission station is uniquely identified in a statistical appendix, which provides information on the mission's size (number of students, of missionaries, etc.) and a detailed record of its activities and investments. For example, we know whether each mission had a printing press, a school, or a health facility. The exhaustive list of variables and a reproduction of one page of the statistical index are provided in the online

\footnotetext{
20 "The curriculum does not mention condoms and provides only limited scope for teachers to discuss protected sex in response to students' questions. It does not cover partner selection, and although they cover love relationships between same age boys and girls, the official textbooks do not mention cross-generational relationships (and their associated risk)" (Dupas, 2011).
} 
Appendix to Cagé and Rueda (2016). Our sample of sub-Saharan African missions includes a total of 723 Protestant missions out of which 99 had a dispensary, and 61 had a hospital or a declared doctor.

\subsubsection{Catholic missionary investments}

This paper complements the data from Cagé and Rueda (2016) with new information on Catholic missionary activity. We exploit the information from the 1929 Atlas Hierarchicus, which is the official publication of the Vatican (the Fide service) that inventories Catholic activities worldwide and locates all the Catholic missionary stations in the world on a series of maps (Streit, 1929) ${ }^{21}$ An example of these maps is provided in Figure 2a. The Atlas also gives some statistical information about the investments at the mission level, although it is less detailed than the Protestants' Geography and Atlas of Christian Missions. Notwithstanding this limitation, it does report the location of missionary hospitals; which is enough for the scope of our study.

Our sample of sub-Saharan African missions includes a total of 536 Catholic missions out of which 36 had a hospital.

[Figure 2 about here.]

\subsubsection{Determinants of missionary location and investments}

Figure 3 reports the historical location of both the Catholic and Protestant missions as well as their health investments. To the extent of our knowledge, we are the very first to produce such a dataset. Overall, we provide information for a total of 1,259 missions.

[Figure 3 about here.]

We rely on the aforementioned atlases to construct our data because they are, to the best of our knowledge, the only systematic records of missions and their investments for the entire continent. However, recent research focused on Ghana has shown that this sample is more likely to capture the earlier and better endowed European missions than the later missions led by Africans, which settled in less favored regions, further from the coast, and more suitable to malaria (Jedwab et al. 2018). Although it is difficult to extrapolate from the unique case of Ghana, we acknowledge that

\footnotetext{
${ }^{21}$ Alternatively, we could have used the previous (1913) Atlas Hierarchicus. We chose to focus on the 1929 one because Catholic missionary activity expanded later than Protestant activity. The 1929 Atlas locates significantly more hospitals and missions than the 1913 one.
} 
our approach captures the effect of the European missionary expansion. Nonetheless, we want to highlight that our within-mission approach restricts the analysis to regions that are close to these European settlements and thus locally comparable. In light of Jedwab et al. (2018), a question that arises is whether our effects are mostly channeled through the later expanding network of local missions. This could be the subject of further research, that would suppose the collection of more extensive data, in particular with a larger geographical reach. It is, however, beyond the scope of this paper.

According to this existing literature, European missionaries were disproportionately more likely to locate in geographically favored areas (Johnson, 1967; Nunn, 2010; Akyeampong et al., eds, 2014: Cagé and Rueda, 2016; Jedwab et al., 2018). In the online Appendix summary statistics Table C.3, we perform a t-test on the equality of means for geographic and historical characteristics of towns located near (less than $100 \mathrm{~km}$ ) and far (more than 100km) from the historical mission settlements in our sample. The results confirm that missionary locations are more geographically favored regions with higher precolonial and subsequent population densities.

Due to potential selection in missionary location, our specifications always control for all the geographic and historical characteristics that may have influenced location choice, such as the malaria ecology, proximity to the coast, suitability for rainfed crops, suitability to Tse-Tse fly, and proximity to historical rail lines and explorer routes. More importantly, following Cagé and Rueda (2016) our results on the effects of health investments are carried "within missions", that is to say that we compare within our sample, missions that invested in health with missions that did not 22

Moreover, as we compare missions depending on whether they invested in health, a second concern would be that of endogenous selection into health investments. Table 1 compares the geographic and historical characteristics of missions that did invest in health with those that did not. Protestants and Catholics are analyzed separately. Although the difference for most geographic indicators is not statistically significant, we observe that missions that invested in health facilities were, on average, located in regions that were slightly cooler, closer to the coast (not statistically significant), with lower elevation. The most important difference is pre-colonial population density, which is (at least) twice is high around missions with health facilities. The patterns observed suggest that missions with health investments were set up in more favorable areas, with larger population densities. We also know that urbanization is one of the most significant determinants of HIV prevalence (Fox, 2010; Oster, 2010; Pépin, 2011). In most sub-Saharan African countries, the ratio of

\footnotetext{
${ }^{22}$ In Section 5 we also show that our results are also robust to focusing on the most urbanized areas in our sample.
} 
HIV prevalence is more than twice as high in cities than in rural areas (UNAIDS, 2015, fig. 5). In a country like Côte d'Ivoire, $23 \%$ of the national population lives in Abidjan, but the city accounts for 30 to $50 \%$ of the country's population infected with the disease (UNAIDS, 2015). Therefore, if geographically confounding factors were driving our results, we would expect these locations to have larger, and not smaller HIV risk.

[Table 1 about here.]

Finally, since pre-colonial characteristics also shaped colonial and post-colonial development outcomes (Michalopoulos and Papaioannou, 2013), Table 2 compares pre-colonial marital structures of the missions with and without a health investment. The rationale for this comparison is that these structures shape sexual behaviors that can ultimately determine HIV patterns. We use data from the Ethnographic atlas, and do not observe statistically significant differences in pre-colonial marriage patterns and sexual practices linked to the location of the health investments..

[Table 2 about here.]

\subsubsection{Additional historical controls}

We compute the distance to 1400 and 1800 cities using GIS and the information on the location of cities provided by Nunn and Wantchekon (2011). Information on explorer contact and railway contact is also from Nunn and Wantchekon (2011).

Furthermore, we control for the tsetse fly suitability index (TSI) developed by Alsan (2015). The tsetse transmits a parasite harmful to humans and lethal to livestock, and has been shown to affect current economic performance (Alsan, 2015). The TSI is the standardized value of the steady-state tsetse population, a larger number indicates a climate more suitable to the fly.

Finally, we collect information on the location of the colonial hospitals. We compute this information from the British colonial statistical records. While we do not control for colonial hospitals in our preferred empirical specification, we use this information in Section 6 when discussing the channels explaining persistence.

\subsection{Contemporary data}

Our analysis relies on the individual-level data from the Demographic and Health Surveys (DHS) distributed by USAID. The DHS are standardized nationally representative surveys in develop- 
ing countries. Women and men answer questions related to their anthropometrics, living conditions, health, sexual reproduction behaviors, and attitudes and beliefs regarding different health outcomes.

Since the 2000s, the DHS also collect biomarker data on Sexually Transmitted Diseases (STDs). Biomarkers are objective physical or biologic measures of health conditions. Using field-friendly technologies, the DHS surveyors can collect biomarker data on HIV ${ }^{23}$ Hence, our measure of HIV infection is based on actual HIV contamination information, not on self-reported surveys where the mean rates of HIV infection are likely to be severe underestimates ${ }^{24}$ The DHS data also provides information on anemia for women; just like for HIV, biomarker testing is used for anemia, making them comparable. We use anemia in Section 5 to show that our result are specific to STDs (i.e. not driven by poorer health conditions in general).

We use the DHS data for sub-Saharan African countries where we have at least one missionary hospital reported, and where both GPS information and biomarker data on HIV are provided. Figure 4 a shows the locations of these clusters. There is a total of 344,212 individuals, distributed in 8,498 clusters distributed among 17 countries: Burkina Faso, Burundi, the Democratic Republic of Congo, Cameroon, Ethiopia, Gabon, Guinea, Kenya, Liberia, Lesotho, Malawi, Rwanda, Senegal, Swaziland, Uganda, Zambia, and Zimbabwe. The information is collected in several rounds, from 2003 to 2014 . The surveys are not systematically carried for all countries every year, so each country appears 1 to 3 times in the sample 25

The DHS now also releases geospatial covariates for all the clusters for which it provides GPS coordinates. We rely on these data to obtain geocovariates that are standard in the literature. For each location, we observe land characteristics (drought episodes, aridity, rainfall, temperature, malaria ecology, etc.), average night-time luminosity, and proximity to water sources, among others. Importantly, this source gives information on the average travel time to a major urban center. This variable captures urbanization and also connectedness to the infrastructure network, which is of particular interest to us, as Oster (2010) shows that road density is an important determinant of HIV prevalence.

\footnotetext{
${ }^{23}$ Dried blood spots (DBS) on filter paper are increasingly used for HIV testing. This method of specimen collection has eliminated the need for cold chain and/or refrigeration of specimens, reducing considerably the complexity of storage in the field and transport to the laboratory.

${ }^{24}$ Another empirical issue comes nonetheless from the fact that individuals have to consent to HIV tests, and their propensity to do so may be affected by colonial medical campaigns (Lowes and Montero, 2017b). Reassuringly, in Section 5. we show that this does not drive our findings.

${ }^{25}$ Most of our regressions restrict the analysis to locations in a $100 \mathrm{~km}$ buffer from a mission station. This reduces the sample to approximately 138,000 to 259,000 individuals (depending on the specification), distributed among approximately 3,700 to 6,500 clusters.
} 
[Figure 4 about here.]

\section{Empirical analysis}

In this section, we document the relationship between missionary activity and HIV prevalence.

\subsection{Specification}

To examine the correlation between proximity to missions (with and without health investments) and HIV / AIDS prevalence, we estimate the following equation:

$$
y_{i r c t}=\mathbf{D i s}_{r}^{\prime} \boldsymbol{\beta}+\mathbf{X}_{\mathrm{irt}}^{\prime} \boldsymbol{\gamma}_{\mathbf{1}}+\mathbf{W}_{\mathbf{r}}^{\prime} \boldsymbol{\gamma}_{\mathbf{2}}+\zeta_{t}+\theta_{c}+\varepsilon_{i r c t}
$$

where $y_{\text {irct }}$ is a binary variable equal to one if the respondent $i$ is tested positive for HIV, in the DHS cluster $r$, in country $c$, and year $t$, and to zero otherwise. In the remainder of the paper, the DHS clusters are referred to as "towns". Dis $\mathbf{r}$ is a vector of distances. It includes the explanatory variables of interest: the logarithm of the distance between town $r$ and the closest historical mission settlement, and the logarithm of the distance between town $r$ and the closest mission with a health investment (a hospital or a dispensary). Online Appendix Table C.1 presents summary statistics on these distances.

The vector $\mathbf{X}_{\text {irt }}$ contains individual level controls that are not "bad controls" in the sense of Angrist and Pischke (2009): sex, age, age square, and marriage status. Our results are robust to introducing a larger set of controls (accounting for education level status or wealth indicators, see section 4.2). $\mathbf{W}_{\mathbf{r}}$ contains geographical and historical-level controls for town $r$ in country $c$. The geographical controls are distance to the capital city; distance to the coast; the average malaria ecology of the land; the slope of the terrain; the elevation; temperature per month, rainfall per month, aridity, and the length of the growing season in days (these are all from the DHS geocovariates set). We also include the Tse-Tse fly suitability index (Alsan, 2015). The historical controls are the distances to cities in 1400 and 1800; and distance to colonial railways and to initial explorer routes (Nunn, 2008). Because they are potential "bad controls", our baseline specification does not include urbanization proxies, in particular, the average travel time to an urban center that captures both urbanization and connectedness into the transport infrastructure. However, our results are robust to including these controls, and also to restricting the analysis to the most connected areas (see Section 5).

Finally, $\zeta$ and $\theta$ are year and country fixed effects. Unless otherwise stated, all the regressions' 
standard errors are clustered at the town level, and all the regressions restrict the analysis to towns that lie within a $100 \mathrm{~km}$ buffer from a historical missionary settlement (depending on the specification, this is any settlement, a Protestant settlement, or a Catholic settlement).

\subsection{Results}

\subsubsection{Baseline specification}

Long-term effects of mission stations Table 3 shows that proximity to a mission station tends to increase the chances of an HIV-positive test, a result that is driven by Protestant missions. This result holds when we restrict the analysis to towns located within a $100 \mathrm{~km}$ buffer of any mission (Column (4)), a Protestant mission (Column (5)), or a Catholic mission (Column (6)). To address selection in missionary locations, these restrictions are applied to the rest of the regressions in the paper, and we refer to these locations as "towns close to missions".

The results suggest that a ten-percent increase in distance to any mission is associated with a 0.003 unit lower probability of an HIV-positive result (Column (4)). Ceteris paribus, at the median distance to a mission, a $15 \mathrm{~km}$ increase in distance decreases the average probability of HIV positivity by approximately 5\%. Online Appendix Table C.5 reports beta coefficients. It shows that a one-standard deviation increase in the logarithm of the distance to a mission decreases the probability of being tested positive for HIV by 1 to $5 \%$ of a standard deviation, and that this effect is driven by Protestant missions. Table C.6 in the online Appendix reports the results from the same regression when adding potential "bad controls" such as education level (none, primary, or high school) and binary indicators of the respondent's wealth percentile as given by the DHS. The estimates of interest remain unchanged.

Given the large literature on the positive legacy of missionary exposure on development (among others, Nunn, 2010; Gallego and Woodberry, 2010; Woodberry, 2012; Acemoglu et al., 2014; Cagé and Rueda, 2016: Calvi and Mantovanelli, 2018: Valencia-Caicedo, 2018), we think that this result, highlighting potential negative correlation with development, is worth investigating. We acknowledge the potential endogeneity issues, especially urbanization. In Section 6, we find that the results hold also for the most urbanized areas, and explores missions' cultural legacy - Christianity - as a channel to be considered. Furthermore, Section 2 above details how the historical evidence supports this hypothesis. 
Long-term effects of health investments Table 3 shows that being close to historical health investments is associated with lower HIV positivity, whether we consider all missions taken together, or Protestant and Catholic missions separately (Columns (1)-(3)).

Regarding the magnitude of the effects, a ten-percent increase in the distance to a mission with a health investment is associated with a 0.0005-unit increase in the probability of HIV positivity (Column (4)). This positive effect holds both for Protestant (Column (5), 0.0007-unit increase) and for Catholic missions (Column (6), 0.0009 unit increase). This result suggests that, ceteris paribus, at the median distance to a mission that invested in health, a $15 \mathrm{~km}$ increase in distance to the health investment increases the average probability of HIV by approximately 0.7 to $1.2 \%$.

Table ?? shows that a one-standard deviation increase in the log distance to a health investment increases the probability of being tested positive for HIV by 2 to $5 \%$ of a standard deviation. Hence the effect is not only statistically but also economically significant.

\section{[Table 3 about here.]}

Table C.4 in the online Appendix shows that these results are robust to using logit regressions. The subsequent analysis in this section addresses endogeneity threats to the results, proposes solutions to them and discusses the likelihood that all of the results are driven by unobservables.

\subsubsection{Health investments and HIV: identification threats and solutions}

Non-parametric effect of distance Figure 5 shows a local polynomial smoothing of individual HIV test results as a function of the log of distance to a health facility. The figure is consistent with the hypothesis of a positive linear relationship between HIV prevalence and the log-distance of the health investment. HIV tends to be smaller on average in regions close to health stations, up to approximately 10 to $15 \mathrm{~km}$, which is a walking distance to a health station.

\section{[Figure 5 about here.]}

Figure 6 shows a local polynomial smoothing of individual HIV test results as a function of the $\log$ of distance to a mission. The Figure is consistent with the hypothesis of a negative relationship between HIV prevalence and the log-distance of missions, for distance ranges starting from approximately $2 \mathrm{~km}$. HIV tends to be larger on average in regions close to missions, up to approximately $25 \mathrm{~km}$.

[Figure 6 about here.] 
Endogenous location of missionary investments: matching strategy In order to overcome the challenge of the endogenous location of missions, we use a "within-missions approach": the sample is restricted to regions close to missions. However, it remains possible that our results might be driven by selection of missions into health investments. As Table 1 shows, there are indeed systematic differences between missions with and without health facilities. Missions with health facilities, both Protestant and Catholic, tend to be located in regions that show higher levels of historical development. In particular, these places have higher pre-colonial population density, are located closer to urban centers, and are in places with lower altitude. Notice that such differences should predict higher and not lower prevalence rates around those health investments, as HIV is mainly a disease of urban areas (Oster, 2010; Fox, 2010; Pépin, 2011).

Following Cagé and Rueda (2016), we develop a matching strategy to tackle the possibility of an endogenous selection of missions into health investments. At the mission-level, we regress a binary variable indicating whether missions are endowed with a health investment on all the observable geographic and historical characteristics available at the mission level (these observables correspond the variables reported in Tables 11. Given the nature of our sources, we have much more information for Protestant than for Catholic missions. Therefore, the matching is conducted separately for each of these samples. From this regression we compute the propensity score, which is the estimated probability of a mission station having a health investment. We then match each mission with a health investment to the mission with the closest propensity score using a one-to-one matching. The sample of missions with a health investment is called $H$. The sample of missions that are selected in the one-to-one matching strategy but that do not have a health investment is called $\bar{H}$.

Tables C.7 and C.8 in the online Appendix report the results of the logit regression generating the sample $\{\bar{H} \cup H\}_{r}$. The pre and post-matching statistics are graphically summarized in Figure 7, and reported in the online Appendix tables C.9 and C.10. Reassuringly, there is no statistically significant difference in observables between the two groups. The standard errors in the post-matching statistics are larger because the number of observations drops from all the sample of misions in the pre-matching case, to those in $H$ or $\bar{H}$ in the post-matching case. Online Appendix figure B.4 compares the densities of the propensity score before and after matching. After matching, the two distributions have a common support and are more comparable.

\section{[Figure 7 about here.]}

A map of all the missions in the sample $\{\bar{H} \cup H\}$ as well as all the DHS locations is shown in 
Figure 8. The polygons overlaying the map represent the Thiessen polygons generated by the points $\{\bar{H} \cup H\}$. For each element $h$ in $\{\bar{H} \cup H\}$, the Thiessen polygon associated to $h$ is the geometry such that for all the points in this geometry, the closest element in $\{\bar{H} \cup H\}$ is $h$. These polygons can help us define regions that are "treated" by health facilites and those that are not, depending on whether $h$ belongs to $H$ or to $\bar{H}$.

[Figure 8 about here.]

In order to conduct our analysis with the DHS data, each DHS town is then associated to the closest mission in the sample $\{\bar{H} \cup H\}$. We then construct the following variables:

- "Distance to health or similar ${ }_{r}$ ": the distance from town $r$ to the closest mission station in the sample $\{\bar{H} \cup H\}$.

- "Treat Health" ${ }_{r}$ : a binary variable equal to one if town $r$ is treated by a health investment (i.e. the closest mission in the sample $\{\bar{H} \cup H\}_{r}$ that actually has a health facility, meaning that it belongs to $H$ ). This term captures the treatment effect of being close to a mission with a health investment, compared to the control group, which are similar missions that did not invest in healthcare.

- "Interaction ${ }_{r}$ : is the interaction term

Distance to health or similar $r \times$ Treat health

Equation (2) describes the identification:

$$
\begin{aligned}
\mathrm{y}_{\text {irt }}= & \alpha+\lambda_{1} \text { Distance to health or similar }{ }_{r}+\lambda_{2} \text { Treat }_{\mathrm{H}_{r}}+\lambda_{3} \text { Interaction }_{r} \\
& +\mathbf{X}_{\mathrm{irt}}^{\prime} \boldsymbol{\gamma}_{\mathbf{1}}^{*}+\mathbf{W}_{\mathbf{r}}^{\prime} \boldsymbol{\gamma}_{\mathbf{2}}^{*}+\zeta_{r}^{*}+\theta_{c}^{*}+\varepsilon_{r t}^{*}
\end{aligned}
$$

where the vectors of controls $\boldsymbol{X}_{\boldsymbol{i r t}}^{\prime}$ and $\boldsymbol{W}_{\boldsymbol{r}}$ are the same as before, and $\mathrm{y}_{i r t}$ is a binary variable equal to one if the respondent is HIV positive, and to zero otherwise. This specification aims to disentangle the effect of proximity to a health investment from the effect of proximity to any mission with characteristics similar to those that provided health services.

Table 4 presents the results. First, the estimate $\hat{\lambda}_{1}$ is never statistically significant across the three specifications. This finding reinforces the interpretation of our results in 3 as driven by health investments rather than other historical, geographical, or mission-level characteristics. The treatment 
effect is negative and statistically significant in the three cases. This means that within regions close to missions, people living in towns close to a mission with health infrastructure, are associated with a 2.3 to 5.9 percentage points lower probability of being tested positive for HIV, compared to towns that are close to a mission with similar observable characteristics but without an investment in health. The interaction term is positive for both Catholics and Protestants, but only statistically significant and with large magnitude for Protestants.

[Table 4 about here.]

\subsubsection{Selection on unobservables compared to selection on observables}

Using the insights from Oster (2016), we check the likelihood that our results are driven by the bias due to unobservables. This method, which we implement using her Stata module psacalc, assesses how large the bias due to unobservables should be, compared to that on observables in order to explain away the results. This ratio is called $\delta$. Using the R-max value of 0.13 (30\% higher than our estimated R-squared), we find that selection in unobservables would need to represent $50 \%$ to $150 \%$ of selection in observables to explain away the results. When adding country and year fixed effects as unrelated controls, the estimated $\delta$ is always larger than one. The results are reported in the appendix Table C.11.

\section{Robustness checks}

Our previous section shows that within regions close to missions, proximity to a mission that invested in health is associated with a decrease in the probability of being tested positive for HIV. Similarly, we find that proximity to a Protestant mission in general (without any distinction on the type of investments conducted) is associated with higher probability of being tested positive for HIV. Our interpretation of these results is that Christian missions, through their cultural and medical legacy had an influence on the epidemic nowadays. Although we acknowledge that other factors can be at play, this article aims at showing that the cultural and medical legacy mattered for understanding the long-term correlations that we have uncovered.

This section test the robustness of our results to alternative explanations. Section 6 will discuss the channels of persistence with more details. 
Consent to test Our estimates rely on the availability of HIV test results. One potential issue is that regions with higher mistrust in medicine will have fewer individuals consenting to HIV tests, thus lowering the HIV-positive results. Given the persistence of mistrust in medicine in regions where colonial medical campaigns were established (Lowes and Montero, 2017b), lack of consent in regions close to missions could pose a potential threat to the estimation. Table C.12 in the online Appendix shows that proximity to a missionary station with a health investment is neither a strong nor a statistically significant predictor of consent to HIV testing. If anything, we observe that proximity to a hospital increases the consent to test, but this result collapses and loses statistical significance when decomposing the analysis separately for Protestant and Catholic missions.

Precolonial marriage patterns Traditional marriage patterns matter in the understanding of the HIV epidemic. In particular, the literature has shown that polygamy is associated with a decrease in HIV prevalence, as it tends to "shrink the sex networks" compared to sequential monogamous relationships or non-faithful monogamous relationships (the last are common in our sample) (Reniers and Watkins, 2010). It would be problematic if we found that there were different pre-colonial marriage patterns in regions close to the missions of interest. First, we can remark that most of the sample in the Ethnographic Atlas reports some form of polygamy (Murdock, 1967). Second, Table 2 shows that the Ethnographic Atlas' groups closest to each mission report no statistically significant differences in precolonial sexual and marriage patterns between missions that invested in health and those that did not.

Education The long-lasting effects of missionaries on education have been studied thoroughly (Woodberry, 2004; Acemoglu et al., 2014; McCleary, 2015; Valencia-Caicedo, 2018). If individuals living in regions close to missions with health investments tend to be more educated, then our results could be driven by human capital rather than by differences in sexual behaviors. Although the existing literature has found no systematic relation between education (in general) and STDs at the micro and short-term level (Duflo et al. 2015), we cannot rule out the role of education in the long run. Table C.13 in the online Appendix reports the results of estimating equation (1) when the dependent variable is the number of years of education. As expected, proximity to a mission is correlated with more education. Importantly, we find no statistically significant relationship between proximity to missions that invested in health and the number of years of schooling. It is thus unlikely that all of our effect would be driven by human capital accumulation. 
Non-sexually transmitted diseases and access to healthcare This section explores the possibility that our results could be unspecific to STDs, and capturing other factors that would correlate with systematically worse health around regions where missions settled, in particular Protestant ones.

The DHS do not provide test results for other STDs, but do report other health-related outcomes, mostly for women. The DHS female dataset indeed includes results for anemia tests and a few anthropometric measures. Table C.16 and C.17 in the online Appendix report the results of estimating equation (1) when the dependent variable is a binary variable equal to one if the respondent is either anemic or has stunted growth, and to zero otherwise.

Regarding proximity to missions, the results show that, unlike for HIV, proximity to a mission does not statistically significantly correlate with these health outcomes. If anything, we observe improved outcomes (less positive results of anemia or stunted growth), but the relationship is not significant. Therefore, it is unlikely that our results capture confounders associated with worse health outcomes around missions. Also, we do not find evidence of conflicting effects between proximity to missions and other health outcomes.

Proximity to a health investment is also associated with improved outcomes in particular regarding the likelihood that maternal care is delivered by medically trained specialists (see Table C.14 in the online Appendix). These outcomes go in line with better access to health facilities, a channel that is explored in further detail in the next section. Regarding other diseases, such as anemia or anthropometric measures, the results usually do not meet statistical significance. A possibility is that we do not observe enough variance within regions close to missions on these outcomes because there are no conflicting effects of missionary influence on non-STDS. Similarly, it is possible that better access of health infrastructure alone is not sufficient to improve all health outcomes. Our results would then have to be considered in combination with the safer sexual behaviors observed around missions with health facilities (see section 6). This result would be consistent with the results of Calvi and Mantovanelli (2018) in the case of India.

Central Equatorial Africa and the rest The recent biological history of HIV has emphasized the likely role of health institutions in the early spread of the epidemic in the equatorial central African region, especially around the Congo river. The widespread use of non-sterilized needles in mass health campaigns to treat sleeping sickness, leprosy, and other diseases during colonial times is likely to have been a key vector of transmission for the disease in its early phase. This transmission is what catalyzed the formation of a large-scale epidemic (Pépin, 2011; Lowes and Montero, 2017a: 
Lachenal, 2014). For this reason, proximity to a health mission, where many of these campaigns were also organized, might not have had a positive effect in Central African countries. We examine whether this is the case by considering separately the Democratic Republic of Congo and Gabon, the only countries in our sample where this early history of the epidemic might apply, and the rest of the sample.

Table C.18 in the online Appendix presents the results. Columns (1) to (3) exclude the DRC and Gabon and columns (4) to (6) restrict the analysis to the DRC and Gabon. The previously described results does not hold for Central Africa, with no statistically significant effects. Columns (4) to (6) perform the same analysis, but for non-Central African countries. First, the results for the sample excluding the DRC and Gabon are similar - both in terms of statistical significance and of magnitude - to the ones presented in Table 3 . Second, there is no statistically significant effect of proximity to a health station for DHS locations in the DRC and Gabon. Our result are thus consistent with the biomedical and economic history literature that emphasize the ambiguous effect of colonial medical campaigns on health and trust and medicine around the Congo river.

Controls We show that our results do not depend on the set of controls included. Online Appendix Table C.21 shows that our results are robust to a specification that only includes year and country fixed effects. In this specification, the effect of distance to a health investment remains positive, statistically significant, and of the same order of magnitude as in our baseline set of results. There is a change in the effect of distance to missions, that become larger in absolute terms, negative and statistically significant for all missions, as opposed to just for Protestant.

Urbanization In sub-Saharan Africa, HIV is a disease that is mostly present in urban and wellconnected areas where large numbers of people transit (Pépin, 2011: Oster, 2012). Given the large evidence of the long-term legacy of missions on long-term development, there is a possibility that our effects, in particular the long-term worsening of HIV around Protestant missions, are entirely driven by modernization.

First, we address this issue regarding missions that invested in health. The new geocovariates in the DHS (available since 2017) report the traveling connecting time to a urban area for all the geocoded DHS clusters. This variable captures both urbanization and connectedness into the transport infrastructure network, which are the key drivers of the relationship between HIV and modernization. Table C.19 in the online Appendix shows that distance to a health investment is 
associated with an increase in travel time ${ }^{26}$ Therefore, if modernization was the unique channel at play, we would expect proximity to a health investment to be associated with larger, and not lower HIV prevalence.

Table C.20 in the online Appendix reports the result of estimating our baseline equation, but in a sample restricted to the $10 \%$ most urbanized and connected clusters in the DHS. It shows that our results hold when applying this restriction. In this sample, proximity to a mission, both Catholic and Protestant, is associated with increased chances of HIV; whereas proximity to a health investment is associated with lower chances. Therefore, it seems plausible to think that urbanization and modernization are not completely driving the result.

Modernization is a channel that we acknowledge in the interpretation of our results, in particular the long-term worsening risk of HIV close to Protestant missions. The relationship between HIV and modernization has been highlighted in the literature (Fox, 2010; Pépin, 2011, among others). Our results can then be seen as further quantitative evidence for this colonial origins of the disease, thus adding nuance to the view that the missionary legacy was solely positive for development. However, the results in Table ?? also suggest that within urbanized areas, there are long-term effects of missionary presence. The goal of Section 6 is to explore further channels of persistence, in particular relating to conversion to Christianity, sexual behaviors, and the persistence of health infrastructure.

\section{Channels}

Taken together, the results of this article show that historical missionary activity has heterogeneous effects on HIV today. In this section, we discuss the channels that could explain the relationship between missionary presence, missionary health investments and HIV prevalence.

First, we aim at getting a clearer understanding of the persistent effect of missionary health investments on HIV prevalence. To do so, we explore the possibility of persistence in infrastructure in the medium term by using the location of the colonial hospitals (we collect this information until 1926 from the British colonial statistical records - the so-called Blue Books) and the available geocoded infrastructure data from the DHS. Furthermore, we follow Calvi and Mantovanelli (2018) and analyze whether there is persistence in health habits, and in particular sexual behaviors.

\footnotetext{
${ }^{26}$ The correlation between travel times and HIV status, conditional on our stated individual and geographic covariates is of $-0.0005(\mathrm{p}<0.00001)$. This means that a one-hour increase in travel times statistically significantly correlates, conditional on observables, with a $5 \%$ increase in the mean probability of being tested positive for HIV.
} 
Second, we wish to investigate the negative relationship between missionary presence and HIV, in particular for Protestant missions. We hypothesize that conversion is a possible explanatory channel. Christianity outlasted missions, and the historical literature emphasizes that Protestant missions, the ones that actually robustly correlate with increased HIV likelihood, were much more successful than Catholics in their initial conversion enterprise (Foster, 2013).

The establishment of a Christian community could have had an impact on HIV prevalence for three main reasons. First, conversion disrupted existing family structures. Polygamy was the dominant (above 90\%) family structure before colonization (Murdock, 1967), which has been shown to be associated with lower prevalence of HIV because it creates smaller units of frequent sexual interaction compared to serial monogamy or non-faithful monogamy (Reniers and Watkins, 2010). Second, early conversion in large numbers gave growing importance to Christian institutions; today, contemporary Christian leaders, by opposing or avoiding the discussion about safer sex practices might have impeded a reduction in the spread of the disease. Mash and Mash (2013) show that local churches have an active role in the contemporary design of HIV-prevention campaigns, that affect Christians and non-Christians, and that they encounter difficulties when addressing the topics about safer sex. Third, even if individual behaviors exhibit minor differences, initial differences in prevalence between groups can exacerbate over time when groups constitute relatively separate "sex markets" (Trinitapoli and Weinreb, 2012, Chap. 2).

While we do not think that conversion is the only explanatory channel, this section aims at showing that it is nonetheless one to be considered.

\subsection{The persistent effect of missionary healthcare}

In Section 4.2, we have showed that within regions close to missions, proximity to a mission that invested in healthcare is associated with lower HIV prevalence, and it is unlikely that this relationship is fully driven by unobservables. In this section, we wish to understand the channels through which such correlation can operate.

Infrastructure in the medium term To understand whether the positive relationship between distance to missionary health stations and HIV prevalence can be driven by persistence in health infrastructure, we collect information on the location of British colonial hospitals up to the mid-1920s from the British African Blue Books. This information is particularly helpful to understand whether our results for the proximity with missionary health stations are driven by persistence in health in- 
frastructure, such as missionary hospitals. The focus here is on Protestant health stations given that the information we have on hospitals in the 1920s is restricted to former British colonies.

The persistence of healthcare infrastructures may be an important explanatory channel given that HIV prevention policies are implemented in these infrastructures. Moreover, other health policies that can decrease the HIV risk, e.g. the provision of treatment for other, treatable, STDs, in particular STDs generating genital ulcers; take place in these hospitals. Protestant and colonial health centers devoted substantial resources for the treatment and the prevention of syphilis (de Sousa et al. 2010: Doyle et al. 2018) 27

First, to capture the persistence of missionary health stations in the medium term, we want to gauge whether the health facilities reported are also entered as health facilities in the colonial statistics. This could arrive for the larger hospitals, if they started receiving colonial funds or even became colonial public services (Good, 1991; Doyle et al., 2018). The first row in table 5 gives the average number of colonial health facilities reported in the Blue Books inside a $10 \mathrm{~km}$ buffer of mission stations. The numbers are larger, albeit no statistically significantly so, around missions with health facilities.

\section{[Table 5 about here.]}

Second, Table 6 records the results from the same analysis ran in Table 3 , but replacing the distance to missionary health stations with the distance to any health center (missionary or colonial). Because the data on the location of colonial hospitals comes from the British Blue Books, the sample is restricted to former British colonies. Columns (1) and (2) show that the results are similar to those in our baseline regression. The results for Catholic health stations are not significant, which can be due to the sample restriction.

[Table 6 about here.]

Infrastructure in the long run The DHS conducts a survey called "Service Provision Assessment" (SPA) that provides an overview of countries' health service delivery, such as the range of services (child health, family planning, etc.) offered per health facility or per region. This survey is geocoded in four of our sample's countries: Kenya, Malawi, Tanzania, and Sénégal. The patterns observed in this limited sample are in line with the hypothesis of persistence in infrastructure. Table 5 gives the

\footnotetext{
${ }^{27}$ According to the UNAIDS, more than $90 \%$ of infant and young child infections occur through mother-to-child transmission, either during pregnancy, labor and delivery, or breastfeeding. This is another possible channel that unfortunately we cannot test for.
} 
average number of health facilities reported in the SPA inside a $10 \mathrm{~km}$ buffer of mission stations. The numbers are statistically significantly much larger (more than double) in buffers around missions that invested in health facilities.

Sexual behaviors To capture the extent of risky sexual behaviors and general knowledge about prevention, we present results on six different outcomes that capture two important dimensions of HIV transmission: (i) paying for sex from sex workers (for men); (ii) monogamy and number of sexual patterns. Figure 9 report the results in graphical form to facilitate comparisons between outcomes ${ }^{28}$ Proximity to a mission with a health station is correlated with a number of safer sexual behaviors. Individuals living in regions close to health investments declare lower use of sex workers' services, over a lifetime or in the year of the questionnaire. Sex workers have been shown to be a crucial vector of transmission of HIV (Pépin, 2011) ${ }^{29}$ Similarly, we show that proximity to a mission decreases the likelihood of being in a monogamous relationship, but also decreases the number of sexual partners other than spouse or the number of sexual partners over the lifetime. This is consistent with a pattern of more isolated sexual networks in polygamous structures that are associated with lower HIV prevalence (as explained in Section 2). We find no evidence suggesting that individuals around historical health facilities exhibit more usage or knowledge about condoms (see online Appendix Figure B.5). Therefore, it seems that proximity to historical health facilities is associated with safer sexual norms that lead to less HIV, rather than with the practice of safer sex.

These results can stem from the fact that sex prevention campaigns are run from the health facilities that have persisted (as shown in the previous section), for instance campaigns informing individuals about the risk of contracting STDs from sex workers. It could also stem from the fact that missions that specialized in health were less active in conversion and disrupted less traditional marriage patterns, in particular polygamy (Good, 1991). We do indeed observe that within regions close to missions, individuals are less likely to be Christian around missions that invested in health (see online Appendix Table C.28).

[Figure 9 about here.]

\footnotetext{
${ }^{28}$ The associated Tables C.22 to C.27 are reported in the online Appendix.

${ }^{29}$ Brodeur et al. (2017) show that the concentration of sex workers in few red-light districts in Thailand during the Vietnam war may explain the outbreak of the HIV epidemics in these areas in the early 1990s.
} 


\subsection{The persistent effect of missionary presence}

The results presented in Table 3 suggest that missionary presence is consistently associated with higher HIV prevalence. This effect is mostly relevant for Protestant missionary presence. Overall, the formation of urban centers around missions and the higher prevalence of HIV in these urban centers is one channel explaining these results. The higher HIV prevalence is, in this sense, a side effect of the "modernization" that occurred in locations where missionaries settled, in particular Protestant missions.

In this section, we argue that conversion may be another important channel. In analyzing the effects of missionary proximity per se, we move away from the strict within-mission analysis that has characterized our previous research (Cagé and Rueda, 2016) and this paper's findings regarding health stations. Although the results should thus be interpreted with caution, we consider important to document conversion - a cultural channel - as an additional factor explaining the persistent effect of missionary presence on HIV.

Missions had a long-run cultural imprint. They indeed started a large-scale conversion process, and Africa exhibits today among the largest growth in Christian population. Table C.28 in the online Appendix corroborates the results by Nunn (2010), who shows that Christian conversion persisted around missions.

To begin with, we compare the sexual behaviors of the Christian (Catholic and Protestant) and of the non-Christian citizens surveyed in the DHS. Table 7 presents the results. We observe that despite being more educated on average than non-Christians, Christians have riskier sexual behaviors. They have more sexual partners over their lifetime and are more likely to use the services of sex workers. Furthermore, they are also less likely to be abstinent before marriage. Despite being more likely to know that condoms lower the chances of transmitting HIV, they are less likely to know where to find them. These results also hold when restricting our sample of analysis to individuals living in urban areas (online Appendix Table C.29).

\section{[Table 7 about here.]}

Focusing on conversion also helps understanding why the worsening of HIV around missions is mostly driven by Protestant missions. According to the historical literature, Catholic missionaries were less successful in their conversion enterprise. The introductions of the 1913 and the 1929 Atlas Hierarchicus state the Vatican's worries about lagging behind Protestant missions in the Empire (Streit, 1913 and 1929). Catholic missions were far less successful in consolidating a local clergy, 
the very effective conversion army of Protestants. This endeavour was indeed particularly challenging given Catholicism's exigency of priest celibacy, and its reliance on Latin for clerical education liturgy before Vatican II in 1959 (Hastings, 1996; Frankema, 2012; Jedwab et al., 2018). Moreover, Catholic missions concentrated in former French and Belgium colonies. Their religious activities were viewed with more hostility by colonial administrators in the French anticlerical political environment before World War One (Woodberry, 2004; Foster, 2013) ${ }^{30}$

Moreover, a comparison within Christians, between Catholics and Protestants, shows that Catholics have safer sexual behaviors. These results are to be interpreted with caution as religious affiliation is not reported in a standardized way across surveys, and categories separating Catholics and Protestants are not always mutually exclusive. Table 8 presents the results. As before, Protestants are significantly more educated and there is virtually no difference regarding urban residence. Catholics exhibit certain riskier behaviors, like a larger age gap inside the household, or a larger number of sex partners. Protestants are nonetheless more likely to use the services of sex workers over their lifetime, which is a very strong determinant of HIV transmission, and less likely to know that condoms lower the chances of HIV contamination. Although it is statistically significant, the difference is quantitatively very small.

[Table 8 about here.]

The statistics in Table 8 can strike as a surprise; after all, the most well-known opposition to anti-HIV policies favoring access to condoms was the Vatican's official publication "Family Values versus Safe Sex", of which the first chapter is entitled "The Catholic Church's Criticism of the Condom in AIDS-Prevention Programmes" (López-Trujillo, 2003). However, the Vatican's positions do not necessarily reflect the diversity of practices in the field. Furthermore, our data do not allow us to control for the intensity of religiosity, nor to decompose accurately the effects between different denominations of Protestants that can substantially differ in prevalence and sexual behaviors (Trinitapoli and Weinreb, 2012). Further research could aim at understanding this particular point.

To test the plausibility of conversion as one explanatory channel, we run the same regressions as those in Table 3, and add an interaction term between distance to the mission and religion, as well as a religion binary variable. We pool all Christian denominations together into one single

\footnotetext{
${ }^{30}$ Foster shows how, in Sénégal, due to a lack of trained colonial personnel and a poor understanding of local languages and customs, the French colonial administrations relied on local - mostly Wolof - Muslim chiefs to enforce their authority, which gave in turn more power to Islam and created incentives for colonial officers to push back against conversion. Missionaries were asked to focus on their charitable enterprises (dispensaries and schools), and decrease evangelization efforts. This was reinforced with France's secularization laws in 1905 (Foster. 2013. Chap. 2)
} 
binary variable because, as explained before, the DHS religious categories are not standardized across waves. The religious variable allows, however, to distinguish precisely between Muslims, Christians, and Traditional religions. The results are reported in Table 9

Columns (1) and (3) show that distance to a Catholic mission does not seem to affect the probability of being tested positive for HIV for either Christians or Muslims. Similarly, the negative effect of distance to a Protestant mission is stronger for Protestants (Columns (2) and (4)), and not statistically significant for Muslims.

\section{[Table 9 about here.]}

Taken together, these results combined with the historical evidence suggest that conversion is a channel of transmission that contributes to explaining the long-lasting effects missions on HIV prevalence. Given data limitations and potential confounders the magnitudes of these findings have to be interpreted with caution. Despite these caveats, the possible negative effect of missionary activity on development through cultural transformations in the colonial context is a relevant finding in the growing economic literature on the, mostly positive, persistent effects of missionary activity.

\section{Conclusion}

Sub-Saharan Africa accounts for more than two thirds of the world's HIV infections. In this paper, we provide new empirical evidence on the long-term effects of missionary activities in sub-Saharan Africa. We highlight two possible countervailing effects of missions on HIV prevalence. On the one hand, their early investments in health facilities have a positive long-term impact on HIV prevalence, through the persistence of infrastructure and safer sexual behaviors. On the other hand, missionaries left a profound cultural imprint: conversion to Christianity increased the risk of contagion by changing family structures and increased exposure to religious institutions that have struggled to effectively address the epidemic.

While the existing literature has mostly focused on missionary presence per se, and on showing their positive consequences for development, we highlight the complexity of their long-term effects. The devil is in the details, and depending on how much missionaries were inclined towards the provision of health services, or how fervent they were, the effect of missionary activity on HIV can vary. 
Finally, we think that our results may help us reflect on contemporary HIV prevention policies. In the United States, religious conservatives strongly support abstinence-until-marriage (AUM) as the central element of HIV prevention efforts, and this policy periodically receives a large share of the Federal funding. In fiscal years 2006 to 2008, one third of the President's Emergency Plan for AIDS Relief's budget was to be spent on abstinence-only campaigns ${ }^{31}$ The conservative focus of HIV prevention is not declining, with American and local religious conservatism converging in the shaping of HIV prevention programs (see e.g. Jappah, 2013). Our long-term perspective suggests that a focus only on "Christianizing" marriage patterns and sexual behaviors is unlikely to be successful.

\footnotetext{
${ }^{31}$ Launched in 2003, PEPFAR is a United States governmental initiative to address the global HIV epidemic, primarily in Africa. When the then congressman Mike Pence's advocated for PEPFAR in Congress in 2003, he said: "Abstinence and marital faithfulness before condom distribution are the cure for what ails the families of Africa. (...) It is important that we not just send the money, but that we send them values that work." Beginning in 2006, PEPFAR specified that 33\% of all prevention funds (and two-thirds of funds for sexual transmission) would be earmarked for AUM programs (see e.g. Santelli et al. 2013).
} 


\section{References}

Acemoglu, Daron, F A Gallego, and James A Robinson, "Institutions, Human Capital, and Development," Annual Review of Economics, 2014, 6, 875-921.

Akyeampong, Emmanuel, Robert H Bates, Nathan Nunn, and James Robinson, eds, Africa's Development in Historical Perspective, Cambridge University Press, 2014.

Alesina, Alberto, William Easterly, and Janina Matuszeski, "Artificial States," Journal of the European Economic Association, 2011, 9 (2), 246-277.

Alsan, Marcella, "The Effect of the TseTse Fly on African Development," American Economic Review, jan 2015, 105 (1), 382-410.

Alsan, Marcella M and David M Cutler, "Why did HIV decline in Uganda?," Working Paper 16171, National Bureau of Economic Research jul 2010.

_ and _ , "Girls? education and HIV risk: Evidence from Uganda," Journal of Health Economics, 2013, 32 (5), 863-872.

Anderson, Siwan, "Legal Origins and Female HIV," American Economic Review, jun 2018, 108 (6), 1407-1439.

Angrist, J D and J S Pischke, Mostly Harmless Econometrics: an Empiricist's Companion, Princeton University Press, 2009.

Baird, Sarah J, Richard S Garfein, Craig T McIntosh, and Berk Ozler, "Effect of a cash transfer programme for schooling on prevalence of HIV and herpes simplex type 2 in Malawi: a cluster randomised trial," The Lancet, apr 2012, 379 (9823), 1320-1329.

Beach, Harlam, ed., A Geography and Atlas of Protestant missions: Their Environment, Forces, distribution, methods, Problems, results and Prospects at the opening of the Twentieth century., Student Volunteer movement for foreign missions, 1903.

Bertocchi, Graziella and Arcangello Dimico, "The Long Term Determinants of Female HIV Infection in Africa: The Slave Trade, Polygyny, and Sexual Behavior," $\{C E P R\}$ Discussion paper, 2015, 10654.

Brodeur, Abel, Warn N Lekfuangfu, and Yanos Zylberberg, "War, Migration and the Origins of the Thai Sex Industry," Working Papers 1706E, University of Ottawa, Department of Economics 2017.

Cagé, Julia and Valeria Rueda, "The Long-Term Effects of the Printing Press in Sub-Saharan Africa," American Economic Journal: Applied Economics, jul 2016, 8 (3), 1-31.

Calvi, Rossella and Federico G Mantovanelli, "Long-Term Effects of Access to Health Care: Medical Missions in Colonial India," Journal of Development Economics, 2018.

Davies, J N P, “This history of Syphilis in \{Uganda\}," Bulletin of the World Health Organization, 1956.

de Sousa, João Dinis, Viktor Müller, Philippe Lemey, and Anne-Mieke Vandamme, “High GUD Incidence in the Early 20th Century Created a Particularly Permissive Time Window for the Origin and Initial Spread of Epidemic HIV Strains," PLOS ONE, 2010, 5 (4), 1-16. 
Dell, Melissa, “The Persistent Effects of Peru's Mining Mita," Econometrica, 2010, 78 (6), 1863-1903.

- and Benjamin Olken, "The Development Effects of the Extractive Colonial Economy: The Dutch Cultivation System in Java," Working Paper 2017.

_ , Nathan Lane, and Pablo Querubin, "The Historical State, Local Collective Action, and Economic Development in Vietnam," Working Paper 2017.

DellaVigna, Stefano and Eliana La Ferrara, "Economic and Social Impacts of the Media," Working Paper 21360, National Bureau of Economic Research jul 2015.

Doyle, Shane, Before HIV: Sexuality, Fertility and Mortality in \{East Africa\}, 1900-1980, Oxford University Press, 2013.

_ , Felix Meier zu Selhausen, and Jacob Weisdorf, "The blessings of medicine? Patient characteristics and health outcomes in a Ugandan mission hopsita, 1908-1970," Technical Report, University of Sussex 2018.

Duflo, Esther, Pascaline Dupas, and Michael Kremer, "Education, HIV, and Early Fertility: Experimental Evidence from Kenya," American Economic Review, feb 2015, 105 (1), 2257-2297.

Dupas, Pascaline, "Do Teenagers Respond to HIV Risk Information? Evidence from a Field Experiment in Kenya," American Economic Journal: Applied Economics, 2011, 3 (1), pp. 1-34.

_ , Elise Huillery, and Juliette Seban, "Risk Information, Risk Salience, and Adolescent Sexual Behavior: Experimental Evidence from Cameroon," Journal of Economic Behavior and Organization, 2018.

Feyrer, James and Bruce Sacerdote, "Colonialism and Modern Income: Islands as Natural Experiments," The Review of Economics and Statistics, may 2009, 91 (2), 245-262.

Foster, Elizabeth Ann, Faith in Empire: Religion, Politics, and Colonial Rule in French Sénégal 1880-1940, Oxford University Press, 2013.

Fox, Ashley M, "The Social Determinants of HIV Serostatus in Sub-Saharan Africa: An Inverse Relationship Between Poverty and HIV?," Public Health Reports, 2010.

Frankema, Ewout H P, "The origins of formal education in sub-Saharan Africa: was British rule more benign?," European Review of Economic History, 2012, 16 (4), 335-355.

Gallego, Francisco A and Robert Woodberry, "Christian Missionaries and Education in Former African Colonies: How Competition Mattered," Journal of African Economies, 2010, 19 (3), 294-329.

Good, Charles M, "Pioneer medical missions in colonial Africa," Social Science E Medicine, 1991, 32 (1), 1-10.

Grosfeld, Irena and Ekaterina Zhuravskaya, "Cultural vs. economic legacies of empires: Evidence from the partition of Poland," Journal of Comparative Economics, 2015, 43 (1), 55-75.

Grosjean, Pauline, "A History Of Violence: The Culture Of Honor And Homicide In The Us South," Journal of the European Economic Association, oct 2014, 12 (5), 1285-1316.

_ and Rose Khattar, "It's Raining Men! Hallelujah?," Discussion Papers 2014-29C, School of Economics, The University of New South Wales jun 2014. 
Hardiman, David, ed., Healing Bodies, Saving Souls, The Wellcome Series in the History of Medicine, 2006.

Hastings, Adrian, The Church in Africa, 1450-1950, Oxford University Press, 1996.

Hemelaar, Joris, "The origin and diversity of the $\{\mathrm{HIV}-1\}$ epidemic," Trends in Molecular Medicine, 2012, 18 (2), 182-192.

Huillery, Elise, "History Matters: The Long-Term Impact of Colonial Public Investments in French West Africa," American Economic Journal: Applied Economics, apr 2009, 1 (2), 176-215.

_ , "The Impact of European Settlement within French West Africa: Did Pre-colonial Prosperous Areas Fall Behind?," Journal of African Economies, mar 2011, 20 (2), 263-311.

Idler, Ellen L, Religion as a social determinant of public health, Oxford University Press, 2014.

Jappah, Jlateh V, “The convergence of American and Nigerian religious conservatism in a biopolitical shaping of Nigeria's HIV/AIDS prevention programmes," Global Public Health, mar 2013, 8 (3), 312-325.

Jedwab, Remi, Felix zu Selhausen, and Alexander Moradi, "The economics of missionary expansion: evidence from Africa and implications for development," Technical Report, University of Sussex 2018.

Jha, Saumitra, "Trade, Institutions, and Ethnic Tolerance: Evidence from South Asia," American Political Science Review, 2013, 107 (4), 806-832.

Johnson, Hildegard B, "The Location of Christian Missions in Africa.," Geographical Review, 1967, 57 (2), 168-202.

Lachenal, Guillaume, Le médicament qui devait sauver l'Afrique: Un scandale pharmaceutique aux colonies Les Empêcheurs de penser en rond, La Découverte, 2014.

Lange, Matthew K, "British Colonial Legacies and Political Development," World Development, jun 2004, 32 (6), 905-922.

López-Trujillo, Alfonso Cardinal, Family values versus safe sex, Pontifical Council for the Family, 2003.

Lowes, Sara and Eduardo Montero, "Blood Rubber: The Effects of Labor Coercion on Institutions and Culture in the DRC.," Working Paper 2017.

_ and _ , "Mistrust in Medicine, the Legacy of Colonial Medical Campaigns in Central Africa," Working Paper 2017.

Mantovanelli, Federico G, " $\{$ Christian\} Missions, $\{\mathrm{HIV}\}$, and Sexual Behaviors in sub-Saharan \{Africa\}," Technical Report, Boston College 2016.

Mash, Rachel and Robert Mash, "Faith-Based Organisations and \{HIV\} Prevention in \{Africa\}: A Review," African Journal of Primary Health Care and Family Medicine, 2013, 5.

McCleary, Rachel, "Oxford Handbook of Latin American Christianity," in "Oxford Handbook of Latin American Christianity," Oxford Handbooks Online, 2015, chapter Protestant. 
Michalopoulos, Stelios and Elias Papaioannou, "Pre-colonial Ethnic Institutions and Contemporary African Development," Econometrica, 2013, 81 (1), 113-152.

_ and _ , "The Long-Run Effects of the Scramble for Africa," American Economic Review, jul 2016, 106 (7), 1802-1848.

_ and _ , "Historical Legacies and African Development," Journal of Economic Literature, forthcoming.

_, Louis Putterman, and David N Weil, "The Influence of Ancestral Lifeways on Individual Economic Outcomes in Sub-Saharan Africa," Working Paper 21907, National Bureau of Economic Research jan 2016.

Miguel, Edward, Sebastian M Saiegh, and Shanker Satyanath, "National Cultures and Soccer Violence," Working Paper 13968, National Bureau of Economic Research apr 2008.

Moscona, Jacob, Nathan Nunn, and James A Robinson, "Keeping It in the Family: Lineage Organization and the Scope of Trust in Sub-Saharan Africa," American Economic Review Papers and Proceedings, 2017, 107 (5), 565-571.

Murdock, George Peter, “Ethnographic Atlas: A Summary,” Ethnology, 1967, 6 (2), 109-236.

Nunn, Nathan, “The Long Term Effects of Africa's Slave Trade," Quarterly Journal of Economics, 2008, 123 (1), 139-176.

_ , "Religious Conversion in Colonial Africa," American Economic Review Papers and Proceedings, may 2010, 100 (2), 147-152.

- and Leonard Wantchekon, "The Slave Trade and the Origins of Mistrust in \{Africa\}," American Economic Review, dec 2011, 101 (7), 3221-3252.

Oster, Emily, "Sexually Transmitted Infections, Sexual Behavior, and the HIV/AIDS Epidemic," The Quarterly Journal of Economics, 2005, 120 (2), pp. 467--515.

_ , "Estimating HIV Prevalence and Incidence in Africa from Mortality Data," The B.E. Journal of Economic Analysis \& Policy, 2010, 10 (1).

_ , "Routes of Infection: Exports and HIV Incidence in Sub-Saharan Africa," Journal of the European Economic Association, 2012, 10 (5), pp. 1025-1058.

_ , "Unobservable Selection and Coefficient Stability: Theory and Validation," Journal of Business Economics and Statistics, 2016, Forthcomin.

Pépin, Jacques, The origins of \{AIDS\}, Cambridge University Press, 2011.

Ranger, Terence $\mathbf{O}$, "Godly medicine: the ambiguities of medical mission in Souteast Tanzania, 1900-1945," Social Science and Medicine, 1981, 15 (3), 261-277.

Reniers, George and Susan Watkins, "Polygyny and the spread of HIV in Sub Saharan Africa: A case of benign concurrency," AIDS, 2010, 24 (2), 299-307.

Santelli, John S, Ilene S Speizer, and Zoe R Edelstein, “Abstinence Promotion Under PEPFAR: The Shifting Focus of HIV Prevention For Youth," Global public health, jan 2013, 8 (1), 1-12. 
Setel, P, A Plague of Paradoxes: AIDS, Culture, and Demography in Northern Tanzania Worlds of Desire: The Chicago Series on Sexuality, Gender, and Culture, University of Chicago Press, 1999.

Streit, Karl, Atlas hierarchicus, Paderbornae : sumptibus typographiae Bonifacianae, 1929.

Thornton, Rebecca L, "The Demand for, and Impact of, Learning HIV Status," The American Economic Review, 2008, 98 (5), pp. 1829-1863.

Trinitapoli, Jenny and Alexander Weinreb, Religion and AIDS in Africa, Oxford University Press, 2012.

UNAIDS, “Ending the \{AIDS $\}$ epidemic: the advantage of cities," Technical Report, \{UNAIDS $\}$ and \{UN-Habitat\} 2015.

Valencia-Caicedo, Felipe, "The Mission: Human Capital Transmission, Economic Persistence, and Culture in South America," Quarterly Journal of Economics, 2018.

Vaughan, Megan, Curing their ills: Colonial power and \{African\} illness, Polity Press, 1991.

Voigtländer, Nico and Hans-Joachim Voth, "Persecution Perpetuated: The Medieval Origins of Anti-Semitic Violence in Nazi Germany," The Quarterly Journal of Economics, 2012, 127 (3), 1339 1392.

Waldinger, Maria, "The long-run effects of missionary orders in Mexico," Journal of Development Economics, 2017, 127, 355-378.

Wantchekon, Leonard, Marko Klašnja, and Natalija Novta, "Education and Human Capital Externalities: Evidence from Colonial Benin," The Quarterly Journal of Economics, 2015, 130 (2), 703-757.

Woodberry, Robert, "The Shadow of Empire: Christian Missions, Colonial Policy, and Democracy in Postcolonial Societies." PhD dissertation, University of North Carolina at Chapel Hill 2004.

Woodberry, Robert D, "The Missionary Roots of Liberal Democracy," American Political Science Review, 2012, 106 (02), 244-274. 


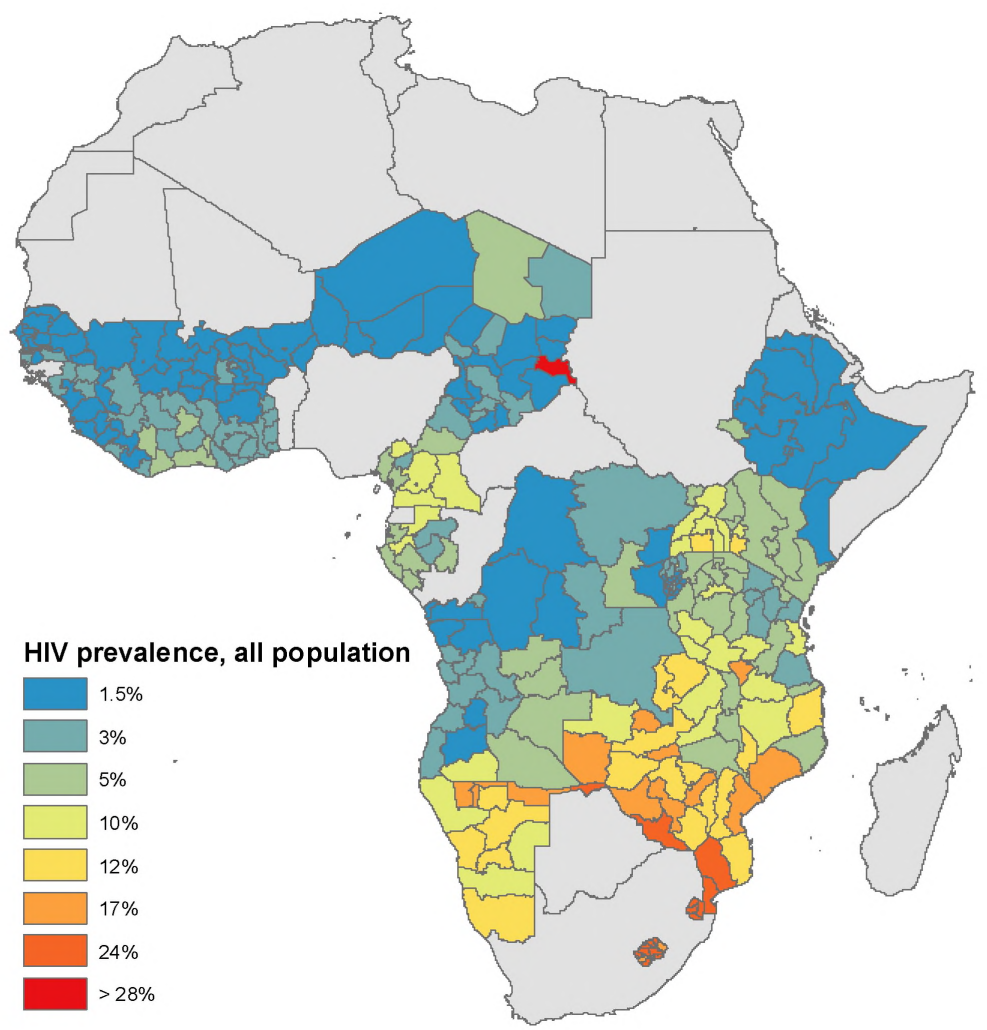

Notes: The figure shows the average HIV prevalence rates at the subnational level computed by the DHS geographic data repository.

Figure 1: HIV prevalence estimates at the subnational level 


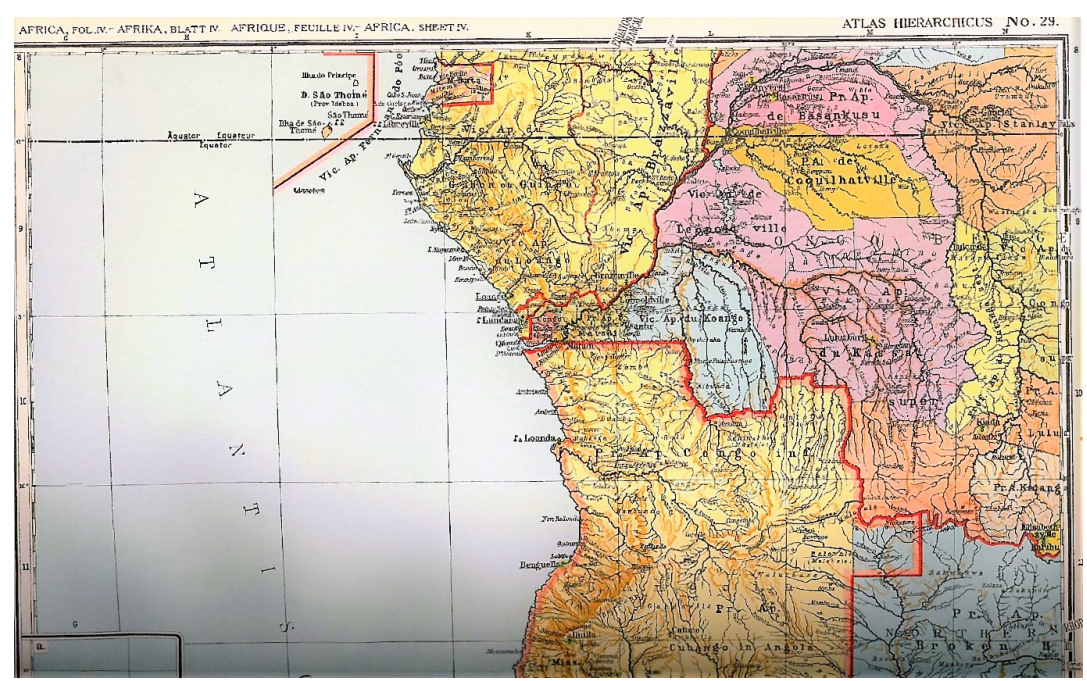

(a) Plate representing the Catholic missionary stations in 1929 (Vatican's Atlas Hierarchicus)

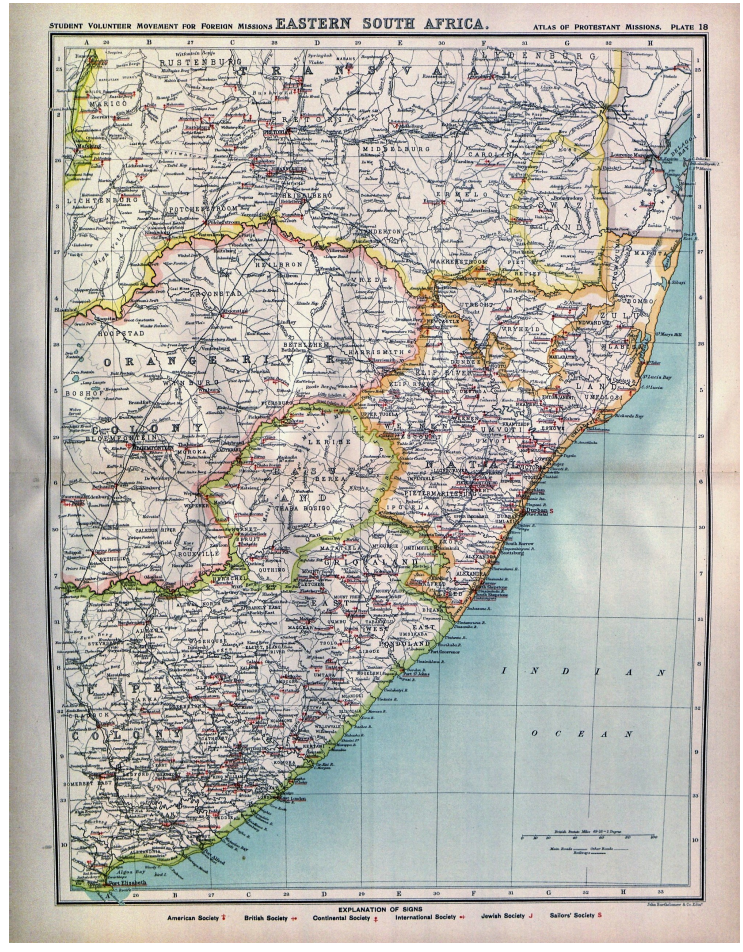

(b) Plate representing the Protestant missionary stations in 1903 (Geography Atlas of Protestant missions)

Notes: The figure reproduces a plate locating Catholic missionary stations (upper figure) and a plate locating Protestant missionary stations (bottom figure).

Figure 2: Plates representing all (Catholic and Protestant) missionary stations 


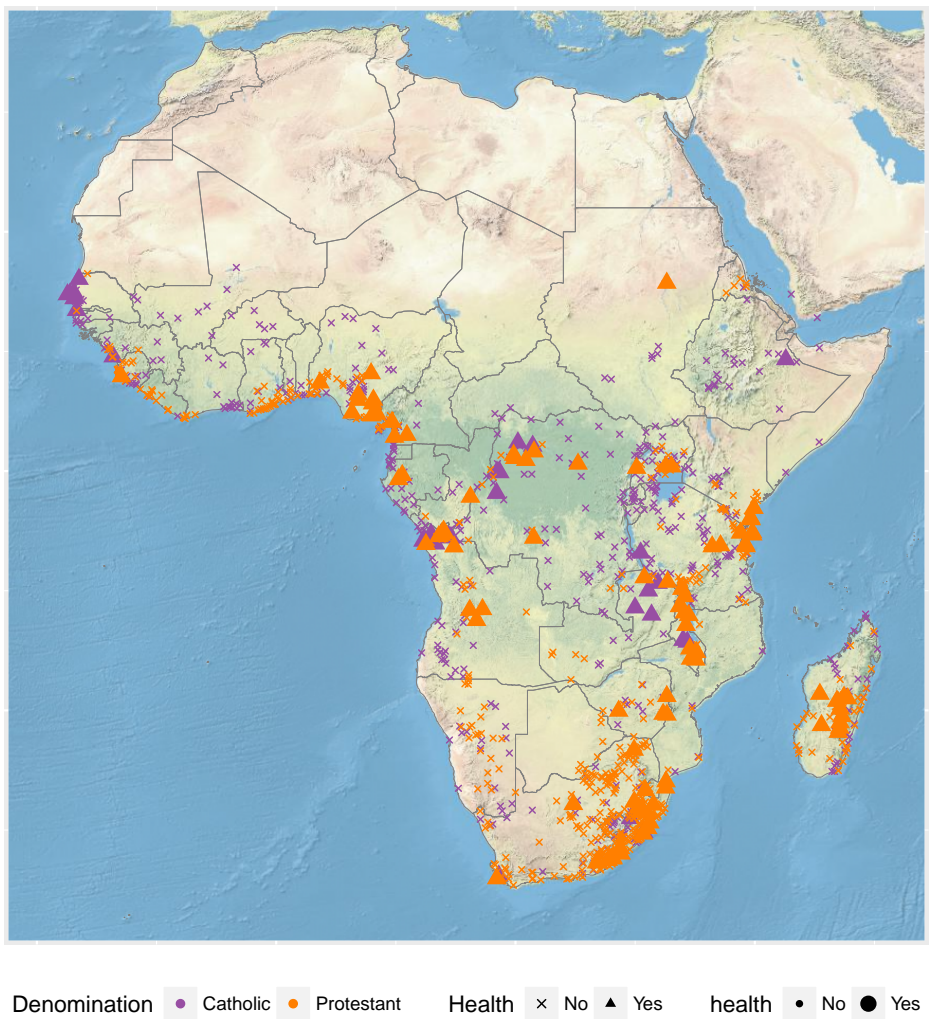

Notes: This map is a digitized and geocoded version of two geography atlas. For Protestant missions, we used digitized and geocoded plates 14 to 18 of Dennis, Beach, and Fahs (1903), from Cagé and Rueda (2016). Health investments include dispensaries and hospitals. For Catholic missions, the map is a digitized and geocoded version of the 1929 Atlas Hierarchicus. The geocoding was conducted by the authors. Health investments include hospitals.

Figure 3: Catholic and Protestant mission stations with and without health investments 


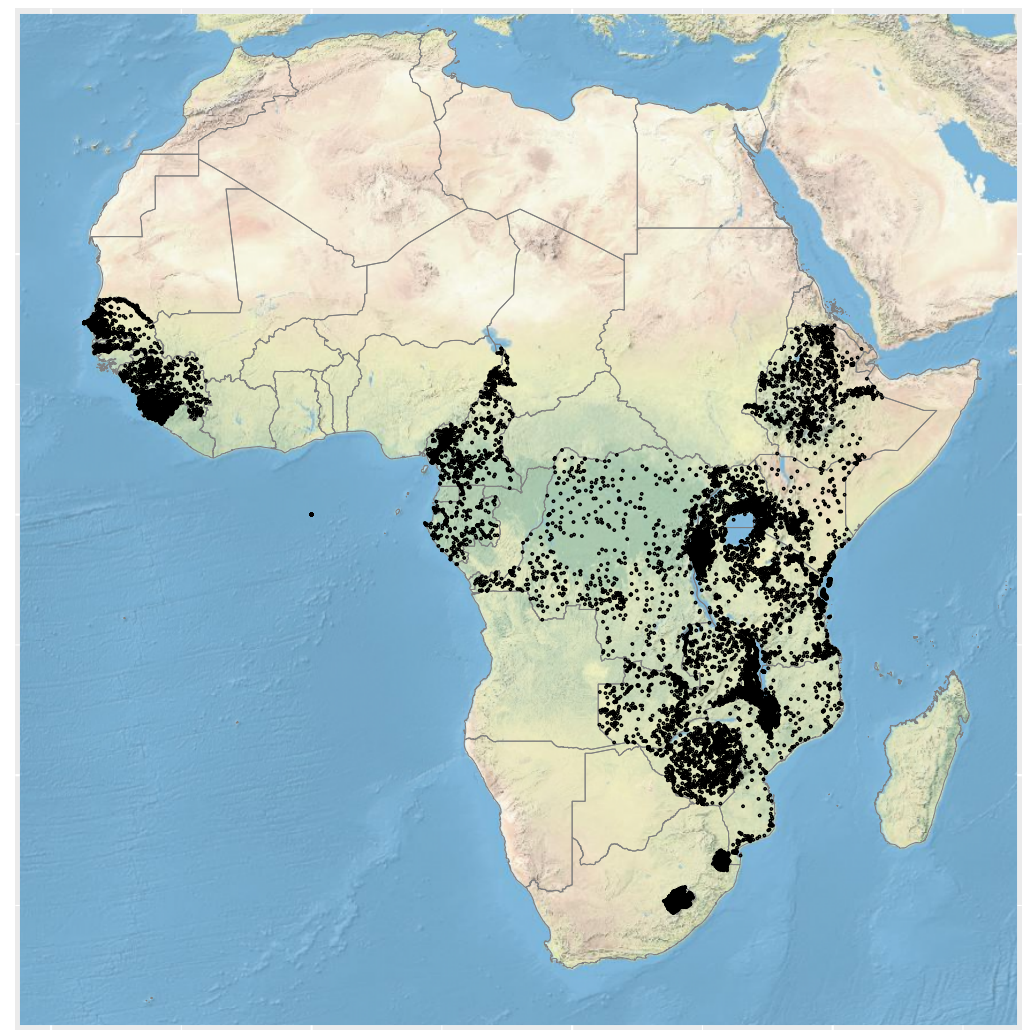

(a) All DHS locations

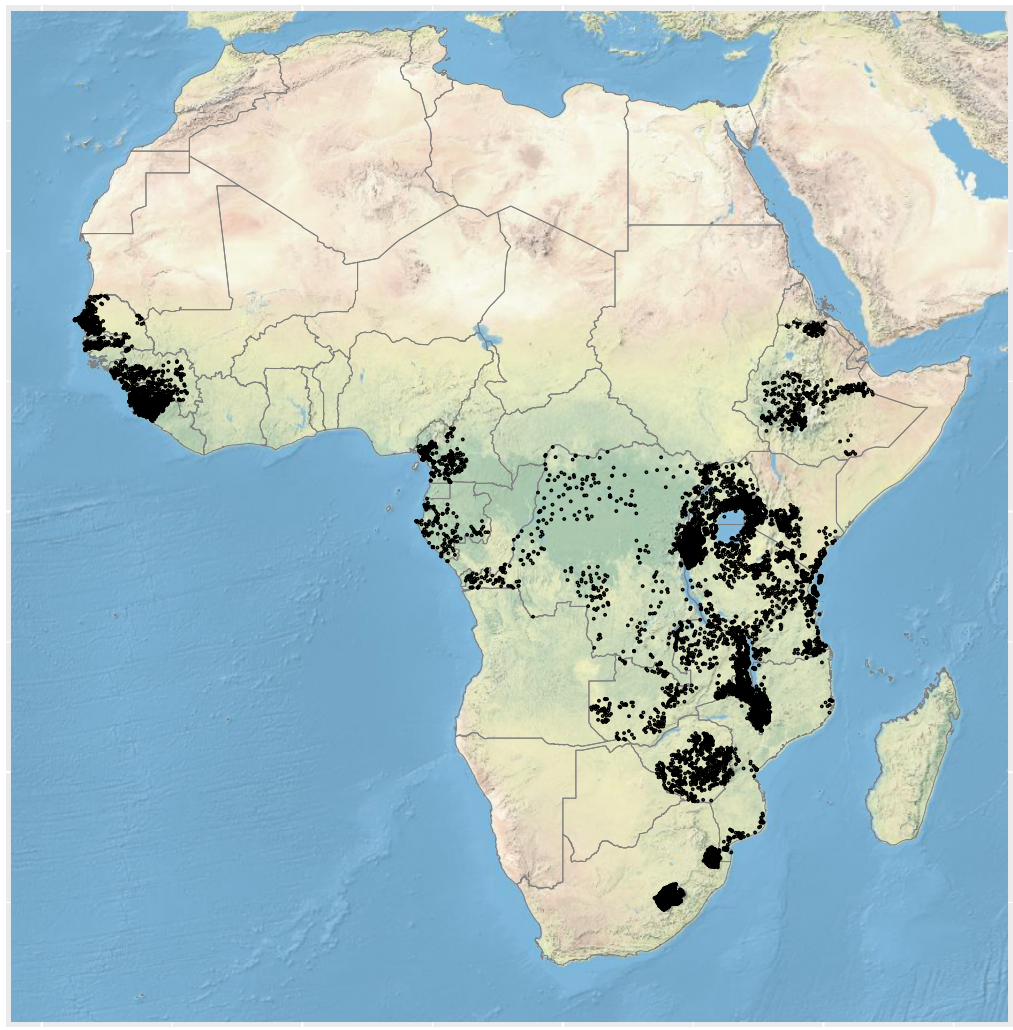

(b) Locations within a $100 \mathrm{~km}$ buffer from a mission

Notes: The figure shows the location of DHS clusters in sub-Saharan Africa that report both HIV biomarker data and GPS information. 


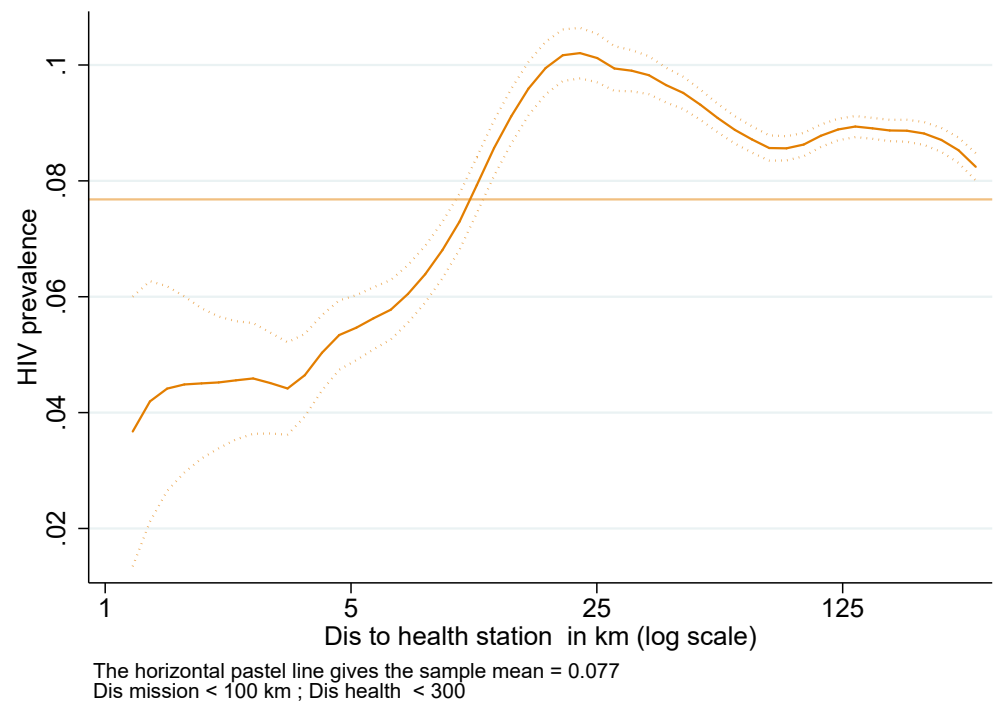

Figure 5: Effect of distance to a missionary station with a health Investment on HIV. Local polynomial regression

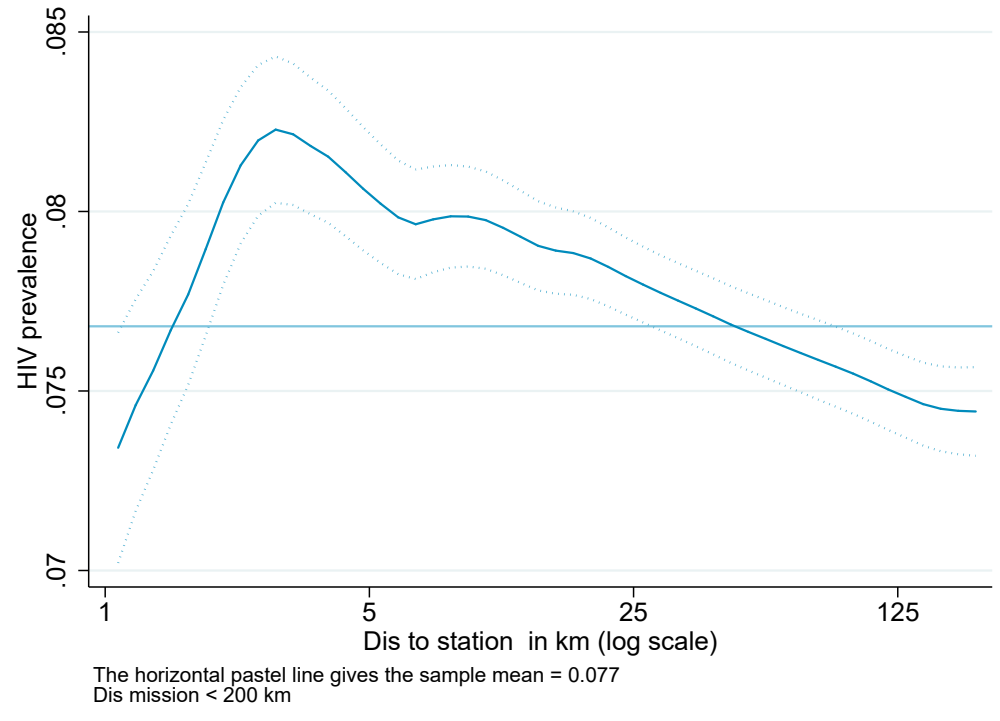

Figure 6: Effect of Distance to a missionary station on HIV. Local polynomial regression 

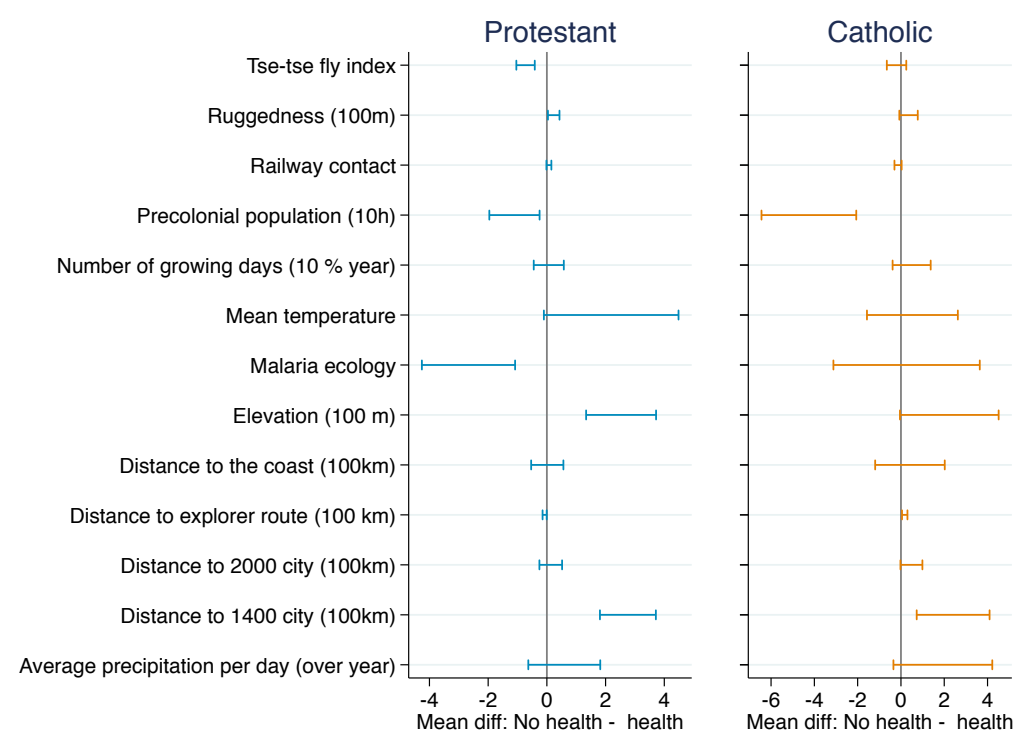

(a) Before matching
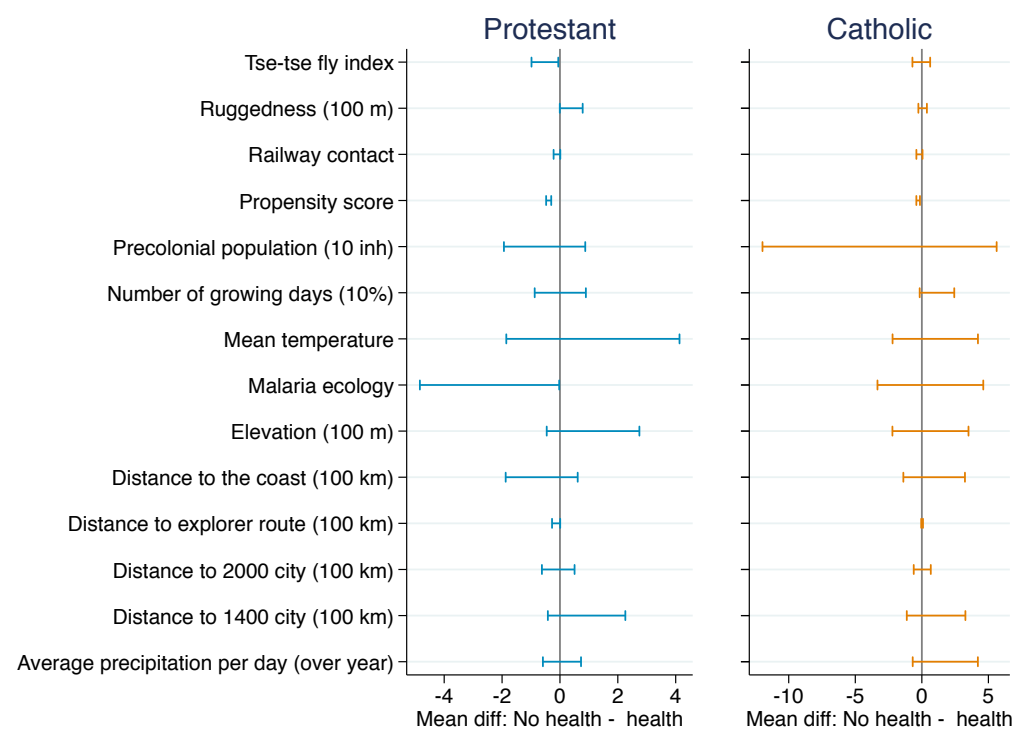

(b) After matching

Notes: The figures report the confidence intervals of the difference in means between the sample of missions without a health facility and those with one (Control group - Treatment group);

Figure 7: Summary statistics. Comparing missions with health facilities and those without before and after matching 


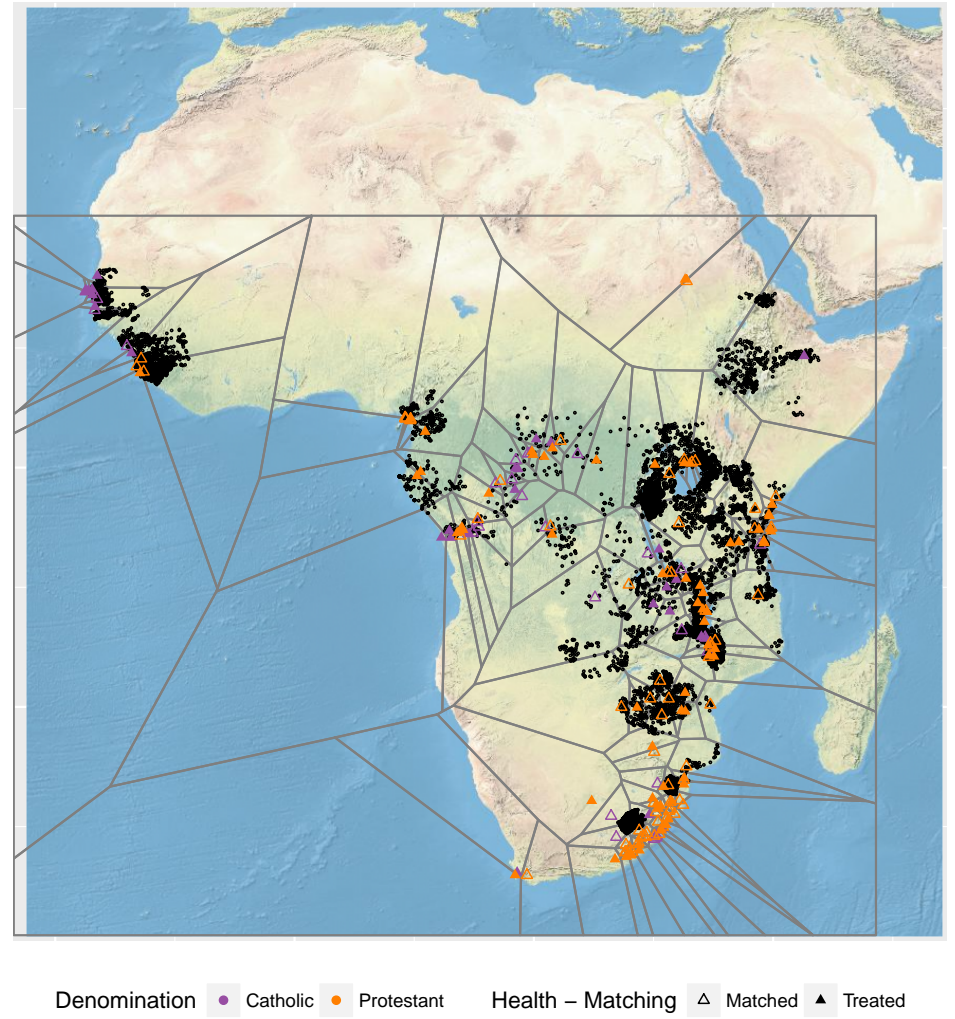

Figure 8: Map of treated and matched missions 


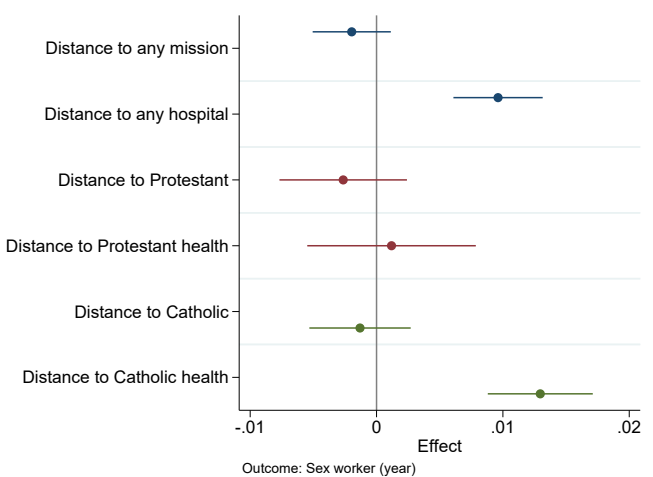

(a) Sex worker in the year

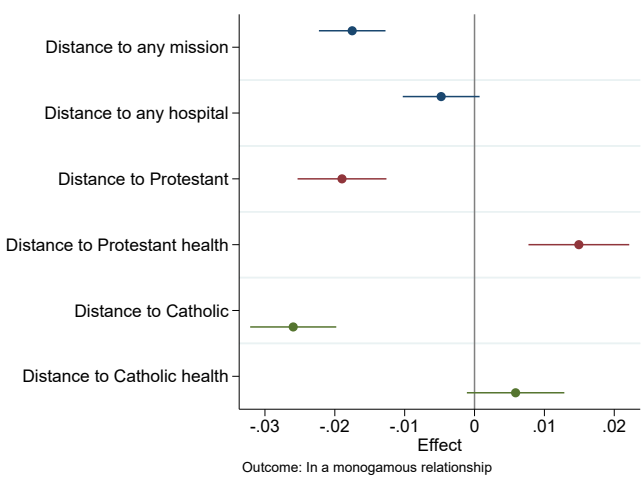

(c) Monogamy

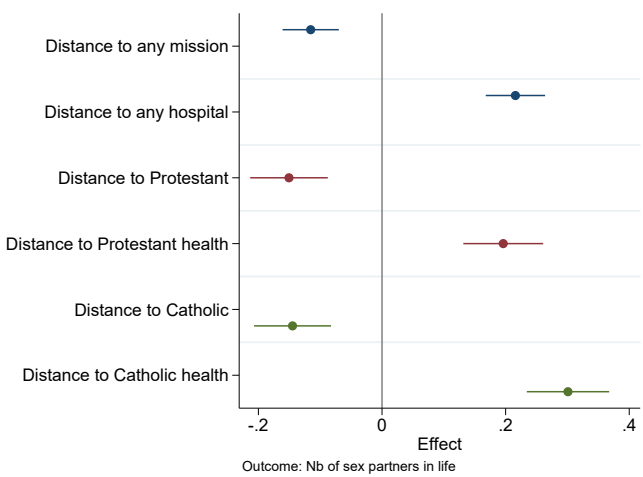

(e) Number of sex partners in life

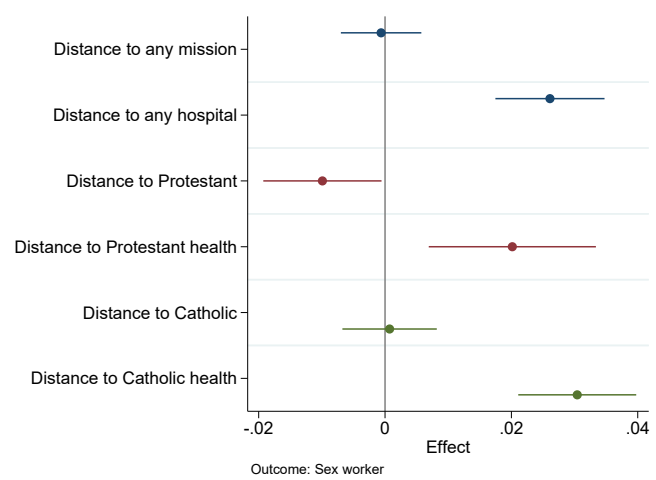

(b) Sex worker - ever in life

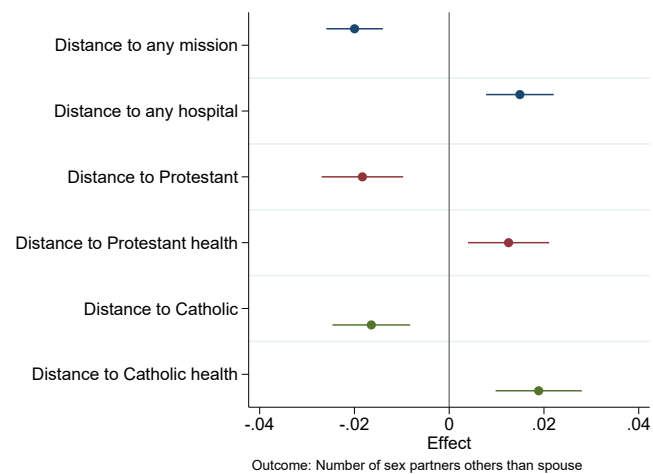

(d) Number of sexual other than spouse

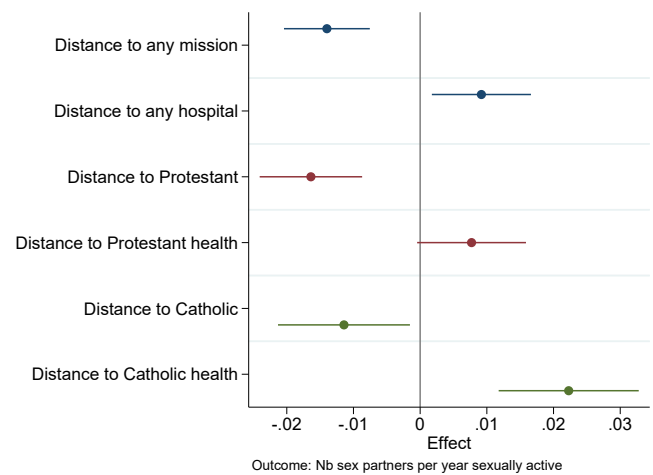

(f) Number of sex partners in life per year sexually active

Notes: The figures report OLS estimates. The point represents the estimated effect and the lines represent the $90 \%$ confidence interval. The unit of observation is an individual. The dependent variables vary for each graph and are reported in the legend. Standard errors are clustered at the town level. Controls are described in the text. All regressions restrict the analysis to regions at least $100 \mathrm{~km}$ close to missions.

Figure 9: Missionary investments and sexual behaviors 
Table 1: Determinants of the location of the health investments

\begin{tabular}{|c|c|c|c|}
\hline & $\begin{array}{c}(1) \\
\text { No Hospital }\end{array}$ & $\begin{array}{c}(2) \\
\text { Hospital }\end{array}$ & $\begin{array}{l}\text { (3) } \\
\text { Diff }\end{array}$ \\
\hline \multicolumn{4}{|l|}{ Panel A: Protestant } \\
\hline Number of growing days (\%) & 53.541 & 52.896 & $\begin{array}{c}0.645 \\
(2.613)\end{array}$ \\
\hline Mean temperature & 18.247 & 16.056 & $\begin{array}{l}2.191^{*} \\
(1.170)\end{array}$ \\
\hline Average precipitation per day (over year) & 3.484 & 2.891 & $\begin{array}{c}0.593 \\
(0.625)\end{array}$ \\
\hline Distance to 2000 city (100km) & 2.695 & 2.563 & $\begin{array}{c}0.132 \\
(0.197)\end{array}$ \\
\hline Distance to the coast $(100 \mathrm{~km})$ & 2.252 & 2.239 & $\begin{array}{c}0.014 \\
(0.280)\end{array}$ \\
\hline Elevation & 760.469 & 507.614 & $\begin{array}{c}252.855^{* * * *} \\
(60.775)\end{array}$ \\
\hline Ruggedness & 92.727 & 69.410 & $\begin{array}{c}23.317^{* *} \\
(10.029)\end{array}$ \\
\hline Malaria ecology & 5.132 & 7.802 & $\begin{array}{c}-2.670^{* *} \\
(0.810)\end{array}$ \\
\hline Railway contact & 0.246 & 0.177 & $\begin{array}{c}0.069 \\
(0.043)\end{array}$ \\
\hline Distance to explorer route $(100 \mathrm{~km})$ & 0.136 & 0.212 & $\begin{array}{c}-0.076^{* *} \\
(0.036)\end{array}$ \\
\hline Precolonial population & 11.060 & 22.101 & $\begin{array}{c}-11.041^{* *} \\
(4.369)\end{array}$ \\
\hline Distance to 1400 city $(100 \mathrm{~km})$ & 8.995 & 6.235 & $\begin{array}{c}2.760^{* * *} \\
(0.486)\end{array}$ \\
\hline Distance to 1800 city $(100 \mathrm{~km})$ & 15.923 & 10.348 & $\begin{array}{c}5.575^{* * *} \\
(0.989)\end{array}$ \\
\hline Tse-tse fly index & -0.716 & 0.010 & $\begin{array}{c}-0.726^{* * *} \\
(0.160)\end{array}$ \\
\hline Observations & 610 & 113 & 723 \\
\hline \multicolumn{4}{|l|}{ Panel B: Catholic } \\
\hline Number of growing days (\%) & 61.752 & 56.812 & $\begin{array}{l}4.940 \\
(4.488)\end{array}$ \\
\hline Mean temperature & 22.465 & 21.936 & $\begin{array}{c}0.529 \\
(1.071)\end{array}$ \\
\hline Average precipitation per day (over year) & 12.781 & 10.845 & $\begin{array}{l}1.936 \\
(1.165)\end{array}$ \\
\hline Distance to 2000 city $(100 \mathrm{~km})$ & 1.865 & 1.381 & $\begin{array}{l}0.484^{*} \\
(0.259)\end{array}$ \\
\hline Distance to the coast $(100 \mathrm{~km})$ & 4.306 & 3.890 & $\begin{array}{c}0.416 \\
(0.820)\end{array}$ \\
\hline Elevation & 735.735 & 512.416 & $\begin{array}{l}223.318^{*} \\
(116.291)\end{array}$ \\
\hline Ruggedness & 92.665 & 57.506 & $\begin{array}{c}35.159 \\
(21.710)\end{array}$ \\
\hline Malaria ecology & 9.658 & 9.396 & $\begin{array}{c}0.261 \\
(1.725)\end{array}$ \\
\hline Railway contact & 0.699 & 0.833 & $\begin{array}{l}-0.134 \\
(0.085)\end{array}$ \\
\hline Distance to explorer route $(100 \mathrm{~km})$ & 0.281 & 0.106 & $\begin{array}{c}0.175^{* *} \\
(0.064)\end{array}$ \\
\hline Precolonial population & 13.278 & 55.808 & $\begin{array}{c}-42.530^{* * *} \\
(11.171)\end{array}$ \\
\hline Distance to 1400 city $(100 \mathrm{~km})$ & 8.365 & 5.954 & $\begin{array}{c}2.411^{* *} \\
(0.859)\end{array}$ \\
\hline Distance to 1800 city $(100 \mathrm{~km})$ & 10.382 & 14.256 & $\begin{array}{c}-3.874^{* *} \\
(1.564)\end{array}$ \\
\hline Tse-tse fly index & 0.074 & 0.277 & $\begin{array}{l}-0.203 \\
(0.229)\end{array}$ \\
\hline Observations & 512 & 30 & 542 \\
\hline
\end{tabular}

Notes: ${ }^{*} \mathrm{p}<0.10,{ }^{* *} \mathrm{p}<0.05,{ }^{* * *} \mathrm{p}<0.01$. The table compares the characteristics of the places where missions with and without a health investment did locate. Panel A presents the results for Protestant missions, and Panel B for Catholic missions. In both panels, column (1) presents the results for missions without a hospital. Column (27 presents the results for missions with a hospital. In column (3), we perform a t-test on the equality of means (robust standard errors are in parentheses). Variables are described in the online Appendix. 
Table 2: Determinants of the location of the health investments: precolonial marital structures

\begin{tabular}{lccc}
\hline \hline & $(1)$ & $(2)$ & $(3)$ \\
Variable & No Hospital & Hospital & Diff \\
\hline & & & \\
Panel A: Protestant & 0.997 & 1.000 & 0.003 \\
Precolonial polygamous & $(0.059)$ & $(0.000)$ & $(0.006)$ \\
& 0.091 & 0.084 & -0.007 \\
Precolonial nuclear family & $(0.288)$ & $(0.279)$ & $(0.032)$ \\
& 0.072 & 0.032 & -0.041 \\
Precolonial taboo on sex bf marriage (women) & $(0.259)$ & $(0.176)$ & $(0.028)$ \\
& 610 & 113 & 723 \\
Observations & & & \\
& & & \\
Panel B: Catholic & 0.994 & 1.000 & 0.006 \\
Precolonial polygamous & $(0.077)$ & $(0.000)$ & $(0.014)$ \\
& 0.082 & 0.033 & -0.049 \\
Precolonial nuclear family & $(0.275)$ & $(0.183)$ & $(0.051)$ \\
& 0.112 & 0.133 & 0.022 \\
Precolonial taboo on sex bf marriage (women) & $(0.315)$ & $(0.346)$ & $(0.060)$ \\
& 510 & 30 & 540 \\
\hline \hline
\end{tabular}

Notes: ${ }^{*} \mathrm{p}<0.10,{ }^{* *} \mathrm{p}<0.05,{ }^{* * *} \mathrm{p}<0.01$. The table compares the characteristics of the places where missions with and without a health investment did locate. Panel A presents the results for Protestant missions, and Panel B for Catholic missions. In both panels, column (1) presents the results for missions without a hospital. Column (2) presents the results for missions with a hospital. In column (3), we perform a t-test on the equality of means (robust standard errors are in parentheses). The variables are from the Ethnographic atlas. 
Table 3: Missionary Investments and HIV Prevalence: Baseline Specification

\begin{tabular}{|c|c|c|c|c|c|c|}
\hline & \multicolumn{3}{|c|}{ All sample } & \multicolumn{3}{|c|}{ Mission $\leq 100 \mathrm{~km}$} \\
\hline & $(1)$ & $(2)$ & (3) & $(4)$ & (5) & $(6)$ \\
\hline & $\mathrm{b} / \mathrm{se}$ & $\mathrm{b} / \mathrm{se}$ & $\mathrm{b} / \mathrm{se}$ & $\mathrm{b} / \mathrm{se}$ & $\mathrm{b} / \mathrm{se}$ & $\mathrm{b} / \mathrm{se}$ \\
\hline Distance to any mission & $\begin{array}{l}-0.002 \\
(0.001)\end{array}$ & & & $\begin{array}{c}-0.003^{* *} \\
(0.002)\end{array}$ & & \\
\hline Distance to any health & $\begin{array}{c}0.009^{* * *} \\
(0.002)\end{array}$ & & & $\begin{array}{c}0.006^{* * *} \\
(0.002)\end{array}$ & & \\
\hline Distance to Protestant & & $\begin{array}{c}-0.003^{*} \\
(0.002)\end{array}$ & & & $\begin{array}{c}-0.010^{* * *} \\
(0.002)\end{array}$ & \\
\hline Distance to Protestant health & & $\begin{array}{r}0.006^{* * *} \\
(0.002)\end{array}$ & & & $\begin{array}{l}0.007^{* *} \\
(0.003)\end{array}$ & \\
\hline Distance to Catholic & & & $\begin{array}{c}0.003^{* *} \\
(0.001)\end{array}$ & & & $\begin{array}{c}0.003 \\
(0.002)\end{array}$ \\
\hline Distance to Catholic health & & & $\begin{array}{c}0.012^{* * *} \\
(0.002)\end{array}$ & & & $\begin{array}{r}0.009^{* * *} \\
(0.002)\end{array}$ \\
\hline Observations & 240,123 & 240,123 & 240,123 & 173,264 & 100,510 & 149,724 \\
\hline Country and Wave FE & Yes & Yes & Yes & Yes & Yes & Yes \\
\hline Contemporary Controls & Yes & Yes & Yes & Yes & Yes & Yes \\
\hline Historical and Geo controls & Yes & Yes & Yes & Yes & Yes & Yes \\
\hline Clusters & 8,873 & 8,873 & 8,873 & 6,689 & 4,060 & 5,654 \\
\hline R-sq & 0.09 & 0.09 & 0.10 & 0.10 & 0.10 & 0.10 \\
\hline Mean DepVar & 0.07 & 0.07 & 0.07 & 0.07 & 0.09 & 0.07 \\
\hline Sd DepVar & 0.26 & 0.26 & 0.26 & 0.26 & 0.29 & 0.25 \\
\hline
\end{tabular}

Notes: ${ }^{*} \mathrm{p}<0.10,{ }^{* *} \mathrm{p}<0.05,{ }^{* * *} \mathrm{p}<0.01$. The Table reports OLS estimates. The unit of observation is the individual. The dependent variable is a binary variable equal to one if the respondent is HIV positive. Standard errors in parentheses are clustered at the town level. Controls are described in the text. 
Table 4: Missionary Investments and HIV Prevalence: Matching

\begin{tabular}{|c|c|c|c|}
\hline & $\begin{array}{c}(1) \\
\mathrm{b} / \mathrm{se}\end{array}$ & $\begin{array}{c}(2) \\
b / s e\end{array}$ & $\begin{array}{c}(3) \\
b / s e\end{array}$ \\
\hline Treat any health & $\begin{array}{c}-0.023^{*} \\
(0.012)\end{array}$ & & \\
\hline Distance to any health or similar & $\begin{array}{c}0.002 \\
(0.002)\end{array}$ & & \\
\hline Any interaction & $\begin{array}{c}0.001 \\
(0.003)\end{array}$ & & \\
\hline Treat Protestant health & & $\begin{array}{c}-0.059^{* * *} \\
(0.020)\end{array}$ & \\
\hline Distance to Protestant health or similar & & $\begin{array}{l}-0.006 \\
(0.005)\end{array}$ & \\
\hline Protestant interaction & & $\begin{array}{c}0.010^{* *} \\
(0.005)\end{array}$ & \\
\hline Treat Catholic health & & & $\begin{array}{c}-0.032^{* * *} \\
(0.013)\end{array}$ \\
\hline Distance to Catholic health or similar & & & $\begin{array}{c}0.003 \\
(0.002)\end{array}$ \\
\hline Catholic interaction & & & $\begin{array}{c}0.002 \\
(0.003)\end{array}$ \\
\hline Observations & 114,706 & 61,178 & 105,480 \\
\hline Country and Wave FE & Yes & Yes & Yes \\
\hline Contemporary Controls & Yes & Yes & Yes \\
\hline Historical and Geo controls & Yes & Yes & Yes \\
\hline Clusters & 4,861 & 2,823 & 4,117 \\
\hline R-sq & 0.11 & 0.10 & 0.12 \\
\hline Mean DepVar & 0.10 & 0.14 & 0.08 \\
\hline Sd DepVar & 0.30 & 0.35 & 0.27 \\
\hline
\end{tabular}

Notes: ${ }^{*} \mathrm{p}<0.10,{ }^{* *} \mathrm{p}<0.05,{ }^{* * *} \mathrm{p}<0.01$. The unit of observation is the individual. The dependent variable is a binary variable equal to one if the respondent is HIV positive, and to zero otherwise. Standard errors in parentheses are clustered at the town level. All regressions restrict the analysis to regions at least $100 \mathrm{~km}$ close to missions. Controls are described in the text. 
Table 5: Presence of health services around missions with and without health facilities

\begin{tabular}{lccc}
\hline \hline & $\begin{array}{c}\text { No Health } \\
(1)\end{array}$ & $\begin{array}{c}\text { Health } \\
(2)\end{array}$ & Diff \\
\hline Panel A: Protestant missions & & & \\
Hospitals in Blue Books & 0.32 & 0.418 & -0.09 \\
N & 493 & 55 & $(0.16)$ \\
Facilities in SPA & 4.4 & 11.5 & -7.1 \\
N & 50 & 15 & $(3.6)^{* *}$ \\
Panel B: Catholic missions & & & \\
Facilities in SPA & & & \\
N & 3.5 & 10.5 & -6.9 \\
\hline \hline
\end{tabular}

Notes: This table presents the average number of colonial hospitals ("Hospitals in the Blue Books") and health services today ("Facilities in SPA") inside a $10 \mathrm{~km}$ buffer of missions with no health facilities (Column (1)) and missions with health facilities (Column (2)). Samples differ. Only countries in the British Empire are considered for the analysis with the Blue Books. Data availability constraints the analysis for the SPA to Kenya, Malawi, Rwanda, and Sénégal. 
Table 6: Persistence in healthcare : effect of missions and colonial health investments

\begin{tabular}{|c|c|c|c|}
\hline & $\begin{array}{c}(1) \\
b / s e\end{array}$ & $\begin{array}{c}(2) \\
b / s e\end{array}$ & $\begin{array}{c}(3) \\
b / s e\end{array}$ \\
\hline Distance to any mission & $\begin{array}{l}-0.002 \\
(0.004)\end{array}$ & & \\
\hline Distance to any hospital or colonial & $\begin{array}{c}0.012^{* * *} \\
(0.003)\end{array}$ & & \\
\hline Distance to Protestant & & $\begin{array}{l}-0.005 \\
(0.004)\end{array}$ & \\
\hline Distance to Protestant health or colonial & & $\begin{array}{l}0.009^{* *} \\
(0.004)\end{array}$ & \\
\hline Distance to Catholic & & & $\begin{array}{c}0.007 \\
(0.005)\end{array}$ \\
\hline Distance to Catholic health or colonial & & & $\begin{array}{c}0.004 \\
(0.004)\end{array}$ \\
\hline Observations & 81,039 & 63,153 & 63,153 \\
\hline Country and Wave FE & Yes & Yes & Yes \\
\hline Contemporary Controls & Yes & Yes & Yes \\
\hline Historical and Geo controls & Yes & Yes & Yes \\
\hline Clusters & 3,510 & 2,901 & 2,901 \\
\hline R-sq & 0.09 & 0.10 & 0.10 \\
\hline Mean DepVar & 0.16 & 0.17 & 0.17 \\
\hline Sd DepVar & 0.36 & 0.37 & 0.37 \\
\hline
\end{tabular}

Notes: ${ }^{*} \mathrm{p}<0.10,{ }^{* *} \mathrm{p}<0.05,{ }^{* * *} \mathrm{p}<0.01$. The Table reports OLS estimates. The unit of observation is and individual. The dependent variable is a binary variable equal to one if the respondent is HIV positive, and to zero otherwise. Standard errors in parentheses are clustered at the closest mission level. All regressions restrict the analysis to regions at least $100 \mathrm{~km}$ close to missions. Controls are described in the text. The regressions are restricted to former British colonies. 
Table 7: Descriptive statistics: HIV prevalence and sexual behaviors, Christians vs. non Christians (t-test)

\begin{tabular}{|c|c|c|c|}
\hline & $\begin{array}{c}(1) \\
\text { Not Christian }\end{array}$ & $\begin{array}{c}\text { (2) } \\
\text { Christian }\end{array}$ & $\begin{array}{l}\text { (3) } \\
\text { Diff }\end{array}$ \\
\hline HIV positive & 0.035 & 0.085 & $\begin{array}{c}-0.050^{* * *} \\
(0.001)\end{array}$ \\
\hline Abstinent before married & 0.678 & 0.608 & $\begin{array}{c}0.071^{* * *} \\
(0.001)\end{array}$ \\
\hline Age at marriage & 18.967 & 20.201 & $\begin{array}{c}-1.234^{* * *} \\
(0.017)\end{array}$ \\
\hline $\mathrm{Nb}$ of sex partners in life & 2.777 & 3.525 & $\begin{array}{c}-0.749^{* * *} \\
(0.016)\end{array}$ \\
\hline Sex worker & 0.092 & 0.142 & $\begin{array}{c}-0.049^{* * *} \\
(0.002)\end{array}$ \\
\hline Sex worker (year) & 0.032 & 0.047 & $\begin{array}{c}-0.015^{* * *} \\
(0.001)\end{array}$ \\
\hline Age gap bw woman and man & -11.029 & -6.559 & $\begin{array}{c}-4.471^{* * *} \\
(0.027)\end{array}$ \\
\hline Knows condom lowers chances of AIDS & 0.712 & 0.791 & $\begin{array}{c}-0.079^{* * *} \\
(0.001)\end{array}$ \\
\hline Knows a place where to get condoms & 0.486 & 0.230 & $\begin{array}{c}0.256^{* * *} \\
(0.001)\end{array}$ \\
\hline Catholic religion & 0.000 & 0.310 & $\begin{array}{c}-0.310^{* * *} \\
(0.001)\end{array}$ \\
\hline Rural Area & 0.309 & 0.257 & $\begin{array}{c}0.052^{* * *} \\
(0.001)\end{array}$ \\
\hline Years of Schooling & 3.127 & 6.524 & $\begin{array}{c}-3.398^{* * *} \\
(0.010)\end{array}$ \\
\hline Female & 0.674 & 0.668 & $\begin{array}{c}0.006^{* * *} \\
(0.001)\end{array}$ \\
\hline Observations & 273445 & 428559 & 702004 \\
\hline
\end{tabular}

Notes: The Table reports descriptive statistics. The unit of observation is an individual. Column (1) reports the means for non Christians. Column (2) reports the means for Christians. Column (3) performs a t-test on the equality of means. 
Table 8: Descriptive statistics: HIV prevalence and sexual behaviors, Catholics vs. Protestants

\begin{tabular}{|c|c|c|c|}
\hline & $\begin{array}{c}(1) \\
\text { Protestants }\end{array}$ & $\begin{array}{c}\text { (2) } \\
\text { Catholics }\end{array}$ & $\begin{array}{l}\text { (3) } \\
\text { Diff }\end{array}$ \\
\hline HIV positive & 0.091 & 0.072 & $\begin{array}{c}0.019^{* * *} \\
(0.001)\end{array}$ \\
\hline Abstinent before married & 0.608 & 0.606 & $\begin{array}{l}0.003^{*} \\
(0.002)\end{array}$ \\
\hline Age at marriage & 20.088 & 20.479 & $\begin{array}{c}-0.391^{* * *} \\
(0.025)\end{array}$ \\
\hline $\mathrm{Nb}$ of sex partners in life & 3.504 & 3.579 & $\begin{array}{c}-0.075^{* *} \\
(0.023)\end{array}$ \\
\hline Sex worker & 0.148 & 0.130 & $\begin{array}{c}0.017^{* * *} \\
(0.003)\end{array}$ \\
\hline Sex worker (year) & 0.047 & 0.046 & $\begin{array}{c}0.001 \\
(0.001)\end{array}$ \\
\hline Age gap bw woman and man & -6.477 & -6.755 & $\begin{array}{c}0.278^{* * *} \\
(0.034)\end{array}$ \\
\hline Knows condom lowers chances of AIDS & 0.784 & 0.808 & $\begin{array}{c}-0.024^{* * *} \\
(0.001)\end{array}$ \\
\hline Knows a place where to get condoms & 0.232 & 0.226 & $\begin{array}{c}0.006^{* * *} \\
(0.001)\end{array}$ \\
\hline Rural Area & 0.259 & 0.253 & $\begin{array}{c}0.006^{* * *} \\
(0.001)\end{array}$ \\
\hline Years of Schooling & 6.664 & 6.212 & $\begin{array}{c}0.452^{* * *} \\
(0.014)\end{array}$ \\
\hline Female & 0.674 & 0.655 & $\begin{array}{c}0.019^{* * *} \\
(0.002)\end{array}$ \\
\hline Observations & 295802 & 132757 & 428559 \\
\hline
\end{tabular}

Notes: The Table reports descriptive statistics. The unit of observation is the individual. Column (1) reports the statistics for Protestants. Column (2) reports similar statistics for Catholics. Column (3) performs a t-test o the equality of means. 
Table 9: Individual level OLS: Distance to mission, religion interactions, and HIV status

\begin{tabular}{lcccc}
\hline \hline & $\begin{array}{c}(1) \\
\mathrm{b} / \mathrm{se}\end{array}$ & $\begin{array}{c}(2) \\
\mathrm{b} / \mathrm{se}\end{array}$ & $\begin{array}{c}(3) \\
\mathrm{b} / \mathrm{se}\end{array}$ & $\begin{array}{c}(4) \\
\mathrm{b} / \mathrm{se}\end{array}$ \\
\hline Distance to Catholic & 0.002 & & 0.004 & \\
& $(0.002)$ & & $(0.005)$ & \\
Distance to Catholic health & $0.012^{* * *}$ & & $0.012^{* * *}$ & $0.013^{* * *}$ \\
& $(0.002)$ & & $(0.002)$ & $(0.003)$ \\
Distance to Catholic x Christian & -0.000 & & -0.002 & \\
& $(0.002)$ & & $(0.005)$ & \\
Distance to Protestant & & $-0.006^{* *}$ & & 0.002 \\
& & $(0.003)$ & & $(0.008)$ \\
Distance to Protestant health & & $0.010^{* * *}$ & 0.001 & $0.008^{* * *}$ \\
& & $(0.003)$ & $(0.002)$ & $(0.003)$ \\
Distance to Protestant x Christian & & $-0.008^{* *}$ & & $-0.013^{*}$ \\
& & $(0.003)$ & & $(0.007)$ \\
Distance to Catholic x Muslim Dummy & & & -0.003 & \\
& & & $(0.005)$ & \\
Distance to Protestant x Muslim Dummy & & & & -0.012 \\
& & & & $(0.008)$ \\
Christian Dummy & -0.010 & 0.010 & -0.014 & 0.011 \\
& $(0.008)$ & $(0.011)$ & $(0.018)$ & $(0.026)$ \\
Muslim Dummy & & & -0.009 & 0.007 \\
& & & $(0.017)$ & $(0.027)$ \\
\hline Observations & & & & \\
Country and Wave FE & & & & \\
Contemporary Controls & Yes & Yes & Yes & Yes \\
Historical and Geo controls & Yes & Yes & Yes & Yes \\
Mission Clusters & & Yes & Yes & Yes \\
R-sq & 0.11 & 0.12 & 0.11 & 0.12 \\
Mean DepVar & 0.07 & 0.11 & 0.07 & 0.11 \\
Sd DepVar & 0.26 & 0.31 & 0.26 & 0.31 \\
\hline \hline
\end{tabular}

Notes: ${ }^{*} \mathrm{p}<0.10,{ }^{* *} \mathrm{p}<0.05,{ }^{* * *} \mathrm{p}<0.01$. The Table reports OLS estimates. The unit of observation is an individual. The dependent variable is a binary variable equal to one if the respondent is HIV positive, and to zero otherwise. Standard errors in parentheses are clustered at the town level. Controls are described in the text. All regressions restrict the analysis to regions at least $100 \mathrm{~km}$ close to Catholic missions (cols (1) and (3)) or Protestant missions (cols (2) and (4)). 